\title{
OS DIQUES COSTEIROS BÁSICOS E ULTRABÁSICOS ADJACENTES AO CANAL DE SÃO SEBASTIÃO (LITORAL NORTE DO ESTADO DE SÃO PAULO)
}

\author{
Gianna Maria GARDA \\ Johann Hans Daniel SCHORSCHER
}

\author{
RESUMO
}

\begin{abstract}
As porções do Complexo Costeiro adjacentes ao Canal de São Sebastião (litoral norte do Estado de São Paulo) são cortadas por diques máficos de composição básica a intermediária, lamprófiros e traquitos. Os primeiros têm sido correlacionados com os basaltos da Bacia do Paraná, enquanto os lamprófiros são expressões de magmatismo alcalino diferente daquele ocorrido há aproximadamente 80 Ma nas ilhas de São Sebastião, Búzios, Vitória e Montão de Trigo. Este último caracteriza-se por termos mais ácidos, associando-se traquitos e raros fonólitos. O magmatismo básico-ultrabásico alcalino representado pelos lamprófiros estendese ao longo do litoral de São Paulo e do Rio de Janeiro, sendo independente e provavelmente mais antigo que os stocks e maciços alcalinos.
\end{abstract}

\section{ABSTRACT}

The portions of the Precambrian Costeiro Complex adjacent to the São Sebastião Channel (São Paulo State, Brazil) are crosscut by mafic dykes of basic to intermediate composition, lamprophyres and trachytes. The former have been correlated with the basalts of the Paraná Basin, while the lamprophyres are expressions of an alkaline magmatism different from the one that happened approximately $80 \mathrm{Ma}$ ago in the São Sebastião, Búzios, Vitória and Montão de Trigo islands, where more acid terms predominate with associated trachytes and rare phonolites. The basic-ultrabasic lamprophyric magmatism is widespread along the São Paulo and Rio de Janeiro coasts; they are independent from and most likely older than the stocks and alkaline massifs.

\section{INTRODUÇÃO}

A Reativação Wealdeniana (ALMEIDA, 1967) teve início no Jurássico Superior e a ela estão relacionados eventos magmáticos ocorridos em duas fases distintas. A primeira, de caráter básico a intermediário, é representada por diques e sills contemporâneos aos derrames da Bacia do Paraná e aos do fundo da Bacia de Santos. A segunda é representada por stocks ou chaminés e diques de rochas alcalinas. Na Ilha de São Sebastião, por exemplo, HENNIES \& HASUI (1977) distinguiram um primeiro ciclo de magmatismo mesozóico constituído por diques básicos do Cretáceo Inferior e um segundo, de stocks e diques alcalinos, datados do Cretáceo Superior.

Os diques da primeira fase encaixam-se nas rochas pré-cambrianas polimetamorfizadas do Complexo Costeiro e são encontrados ao longo do litoral paulisa e do Rio de Janeiro. Várias ocorrências desses diques foram mapeadas durante projetos de enfoque regional, como os apresentados por FREITAS (1976), SILVA et al. (1977) e HASUI et al. (1978). Entretanto, DAMASCENO (1966) já distinguira um conjunto de lamprófiros entre os diques de composição básica a intermediária que ocorrem na região de Ubatuba.

Por sua vez, COUTINHO et al. (1991) reconheceram vários lamprófiros em meio a diques de diabásio e microdioritos pórfiros, na região compreendida entre a Falha do Camburu e a cidade de São Sebastião (planalto do Juqueriquerê). Da cidade de São Sebastião à Juréia, COUTINHO \& ENS (1992) registraram cerca de 250 diques máficos (lamprófiros alcalinos e ankaramitos, diques de diabásio e termos transicionais para lamprófiros, de olivina basaltos, analcima basanitos e tefritos, de diorito e monzonito pórfiros, e diques formados por uma miscelânea de rochas raras como polzenito, micronorito, traquiandesito e carbonatito), expostos ao longo de estradas e costões no continente e ilhotas próximas. Lamprófiros alcalinos foram descritos por COUTINHO \& MELCHER (1973) na Ilha Montão de Trigo, ocorrendo juntamente com diques de 
sienobasaltos, microshonkinitos e rochas leucocráticas, cortando os corpos de foiaíto e teralito principais. Em "As Ilhas" (próximas à praia de Juquehy e às ilhas das Couves e Montão de Trigo), foi encontrado um dique de silício carbonatito que passa para um carbonatito dolomítico nas bordas. Na Ilha de Alcatrazes, um dique de microteralito gradando para basanito, com $10 \mathrm{~m}$ de espessura e direção $\mathrm{N} 10^{\circ} \mathrm{E}$, corta embrechitos facoidais.

Em direção ao litoral sul do Estado de São Paulo, SILVA et al. (1977) citam que diques alcalinos de menor expressão aparecem em São Vicente, onde os lamprófiros são de caráter ultrabásico, sendo uma variedade limburgítica de um analcima ankaratrito e semelhantes, por seu aspecto geral e composição mineralógica, aos jacupiranguitos. Em Peruíbe, um monchiquito corta migmatitos do embasamento. Em Itanhaém, um dique de provável shonkinito foi datado por AMARAL et al. (1967), que obtiveram uma idade K-Ar de $130 \mathrm{Ma}$. Diques de beforsito de espessura decimétrica são também encontrados naquela região, sendo que ULBRICH \& GOMES (1981) citam a ocorrência de um olivina sövito.

Os lamprófiros têm sido associados tanto ao magmatismo basáltico e intermediário como aos eventos de natureza alcalina. Neste trabalho é feita uma abordagem quanto à geoquímica daqueles diques que ocorrem contíguos ao canal de São Sebastião, utilizando-se os dados de BELLIENI et al. (1990), GARDA (1995) e inéditos.

\section{MATERIAL E MÉTODOS}

Os trabalhos de laboratório e de escritório foram precedidos pelos de campo, cujo principal objetivo foi a coleta de amostras para análise química de rocha total.

A FIGURA 1 apresenta a localização da área de estudo, situada entre as latitudes $23^{\circ} 45^{\prime} \mathrm{S}$ e $24^{\circ} \mathrm{S}$ e longitudes $45^{\circ} \mathrm{W}$ e $45^{\circ} 30^{\prime} \mathrm{W}$ e compreendida pelas folhas 1:50.000 de São Sebastião e Paranabi do IBGE e 1:10.000 da Praia do Guaecá (SF-23-Y-D-VI-3-NO-C) e de São Sebastião (SF-23-Y-D-VI-3-NO-D) do Instituto Geográfico e Cartográfico. O acesso à área se faz de São Paulo a São José dos Campos pela Rodovia dos Trabalhadores ou Rodovia Presidente Dutra (BR-116) e de São José dos Campos a Caraguatatuba pela Rodovia dos Tamoios (SP-99), totalizando aproximadamente $250 \mathrm{~km}$ (este percurso tornou-se mais curto após a construção da
Rodovia Carvalho Pinto). Seguindo-se pela SP-55 (BR-101), chega-se à cidade de São Sebastião, $28 \mathrm{~km}$ a sudeste de Caraguatatuba. A travessia do Canal de São Sebastião é feita por ferryboat, ficando a cidade de Ilhabela a aproximadamente $7 \mathrm{~km}$ do terminal da Ilha de São Sebastião.

\subsection{Trabalhos de campo}

Foram realizadas cinco etapas de campo nos trechos da costa entre a Ponta do Itapuã à Ponta do Araçá, município de São Sebastião, e entre a Ponta da Armação e Praia do Bonete, nas porções ocidental e sul da ilha de São Sebastião.

A amostragem incluiu, sempre que possível, amostras de mão retiradas das bordas e centros dos diques, relacionados na TABELA 1.

\subsection{Trabalhos de laboratório}

\subsubsection{Petrografia}

Seções delgadas, confeccionadas pelo laboratório de laminação do Departamento de Mineralogia e Petrologia do Instituto de Geociências da USP (IG-USP), foram descritas e fotografadas utilizando-se os microscópios Zeiss do Laboratório de Óptica do IG-USP e JENAPOL do Instituto Geológico.

\subsubsection{Geoquímica}

Fragmentos de rocha livres de material de alteração foram britados em britador de mandíbulas de ferro e pulverizados e homogeneizados em moinho de anéis de ágata no laboratório de preparação de amostras do Departamento de Mineralogia e Petrologia do IG-USP.

Os elementos maiores e alguns elementos menores e traços foram analisados por fluorescência de raios $X$ no Laboratório de Geoquímica do Instituto de Geologia e Paleontologia da Universidade de Hamburgo e no Instituto de Geociências da Universidade de Mainz (ambos na Alemanha). Os limites de deteç̧ão fornecidos pelo primeiro laboratório são:

$\mathrm{SiO}_{2}$ e $\mathrm{Al}_{2} \mathrm{O}_{3}: 0,004 \% ; \mathrm{TiO}_{2}: 0,0001 \%$; FeO e MnO: $0,002 \%$; $\mathrm{MgO}$ e $\mathrm{Na}_{2} \mathrm{O}: 0,1 \%$; $\mathrm{CaO}$ : $0,0004 \% ; \mathrm{K}_{2} \mathrm{O}: 0,0003 \% ; \mathrm{P}_{2} \mathrm{O}_{5}: 0,007 \%$; $\mathrm{Ce} \mathrm{e}$ La: 20 ppm; Co: 15 ppm; Ba e Nd: 10 ppm; demais elementos: $5 \mathrm{ppm}$. 


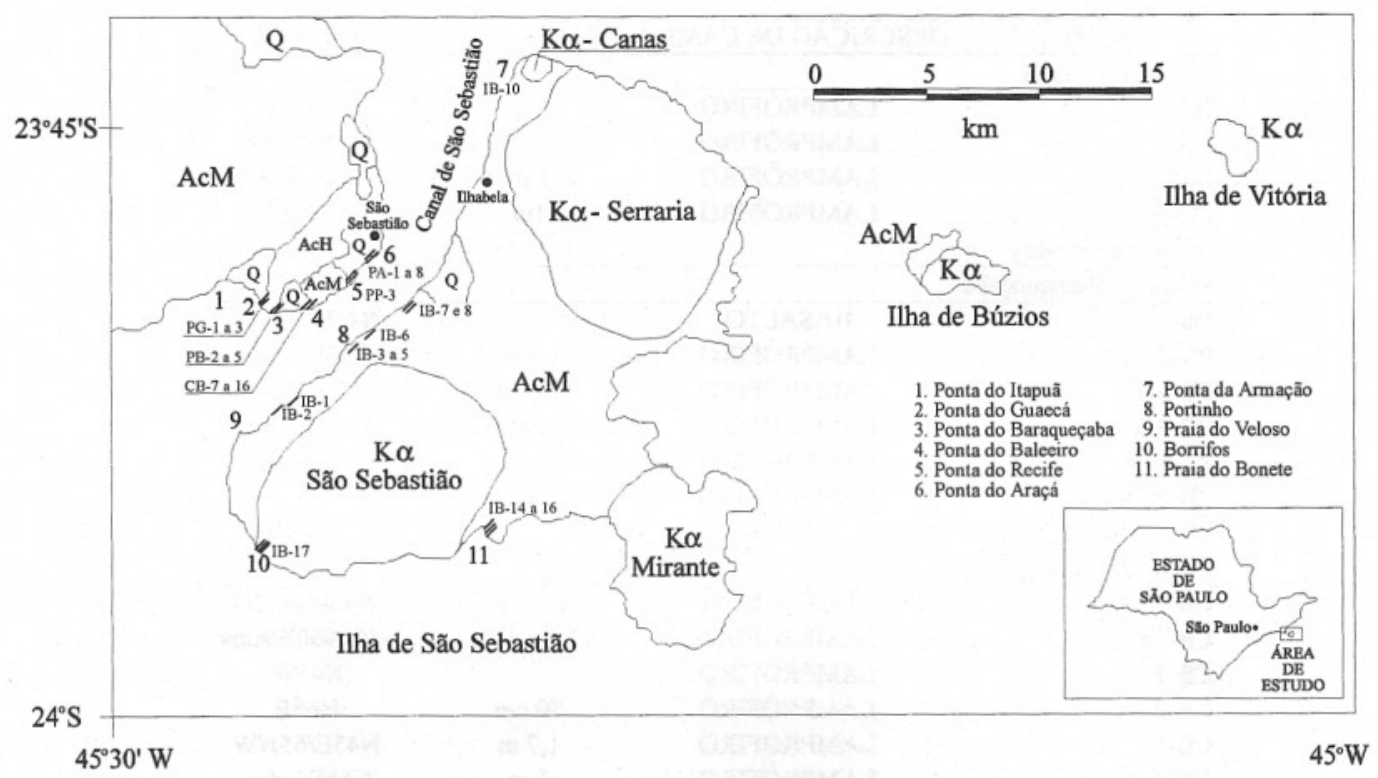

FIGURA 1 - Localização dos diques referidos neste trabalho e mapa geológico simplificado da área de estudo (ALMEIDA et al., 1981, mod.) Rochas arqueanas do Complexo Costeiro: $\mathrm{AcH}=$ granulitos; $\mathrm{AcM}=$ rochas migmatíticas. Mesozóico: // = diques de rochas básicas a intermediárias, lamprófiros e traquitos; $\mathrm{K} \alpha=$ rochas ígneas alcalinas. Q = depósitos quaternários.

Vinte e dois elementos traços (incluindo os terras raras) de cinco amostras pulverizadas foram analisados por ativação neutrônica (NAA) em Becquerel Laboratories (Lucas Heights, Austrália). Os limites de detecção fornecidos pelo laboratório são:

La: 0,1 ppm; Ce: $1,0 \mathrm{ppm}$; Nd: 2,0 ppm; Sm: 0,05 ppm; Eu: 0,1 ppm; Tb: 0,3 ppm; Dy: 1,0 ppm; Ho: 0,3 ppm; Yb: 0,1 ppm; Lu: 0,05 ppm; Ba: 100 ppm; Cs: 0,5 ppm; Hf: 0,2 ppm; $\mathrm{Rb}: 10 \mathrm{ppm}$; Sc: $0,05 \mathrm{ppm}$; Ta: 0,5 ppm; Th: 0,2 ppm.

Os elementos traços de outras cinco amostras foram analisados por espectrometria de massa com fonte de plasma indutivamente acoplado (ICP-MS) na School of Earth Sciences da Australian National University (Canberra, Austrália). O procedimento para preparação das soluções a partir dos pós está descrito em GARDA (1995). Foi preparada uma solução em duplicata de uma das amostras. A comparação dos resultados das duas análises, uma feita no início e outra no fim da seção, forneceu os seguintes desvios padrões:

Cs: 0,01 ppm; Rb: 0,6 ppm; Ba: 30 ppm; Th: $0,06 \mathrm{ppm}$; U: $0,06 \mathrm{ppm}$; Nb: 0,9 ppm; Ta: 0,001 ppm; La: 0,9 ppm; Ce: 7 ppm; Pb: 0,08 ppm; Pr: 0,1 ppm; Sr: 117 ppm; Nd: 0,2 ppm;
Sm: 0,006 ppm; Zr: 3 ppm; Hf: 0,01 ppm; Eu: 0,05 ppm; Gd: 0,04 ppm; Tb: 0,007 ppm; Dy: 0,02 ppm; Li: 1 ppm; Y: 0,5 ppm; Ho: 0,006 ppm; Er: 0,008 ppm; Yb: 0,004 ppm; Lu: $0,0005 \mathrm{ppm}$.

A preparação de pós para análise das razões dos isótopos de $\mathrm{Sr}$ foi realizada na School of Earth Sciences da Macquarie University (Austrália), segundo os procedimentos descritos em GARDA (1995). As análises foram realizadas com o espectrômetro de massa VG354 do Mineral Research Laboratories da CSIRO (Austrália). A normalização das razões isotópicas de $\mathrm{Sr}$ para a correção do fracionamento de massa foi feita com a razão ${ }^{86} \mathrm{Sr} /{ }^{88} \mathrm{Sr}=0,1194 \mathrm{e}$ a razão ${ }^{87} \mathrm{Sr} /{ }^{86} \mathrm{Sr}$ do padrão NBS987 foi $0,710246 \pm 14$. O valor do branco analítico foi de $128 \mathrm{pg}$ (fornecido pelo laboratório e medido em 27/02/1994).

\subsection{Trabalhos de escritório}

Os dados geoquímicos apresentados neste trabalho e os de BELLIENI et al. (1990) foram tratados utilizando-se os programas MICROSOFT EXCEL 4.0, NEWPET (CLARKE, 1993) e MINPET (RICHARD, 1995). 
TABELA 1 - Relação dos diques representados na FIGURA 1.

\begin{tabular}{|c|c|c|c|}
\hline PONTO & DESCRIÇÃO DE CAMPO & ESPESSURA & ATITUDE \\
\hline \multicolumn{4}{|l|}{ Ponta do Guaecá } \\
\hline PG-1 & LAMPRÓFIRO & $1 \mathrm{~m}$ & N50E/subv. \\
\hline PG-1-6 & LAMPRÓFIRO & & N50E/subv. \\
\hline PG-2 & LAMPRÓFIRO & $1 \mathrm{~m}$ & N54E/85SE \\
\hline PG-3 & LAMPRÓFIRO & $\operatorname{lm}$ & N50E/subv. \\
\hline \multicolumn{4}{|c|}{ PG-4 (observado) } \\
\hline \multicolumn{4}{|c|}{ Ponta do Baraqueçaba } \\
\hline PB-1 & BASALTO & & N47E/30NW \\
\hline PB-2 & LAMPRÓFIRO & $1,9 \mathrm{~m}$ & N55E/subv. \\
\hline PB-3-1 & LAMPRÓFIRO & $30 \mathrm{~cm}$ & N45E/subv. \\
\hline PB-3-2 & LAMPRÓFIRO & $50 \mathrm{~cm}$ & N45E/subv. \\
\hline PB-4 & LAMPRÓFIRO & $2 \mathrm{~m}$ & N50E/subv. \\
\hline PB-5 (blocos) & LAMPRÓFIRO & 1,5 a $2 \mathrm{~m}$ & \\
\hline PB-6 (alterado) & & & N55E/W \\
\hline \multicolumn{4}{|c|}{ Ponta do Baleeiro } \\
\hline CB-15 & TRAQUITO & 1 a $2 \mathrm{~m}$ & $\mathrm{~N} 36-46 \mathrm{E} / 30$ \\
\hline CB-16 & LAMPRÓFIRO & 2,5 a $3 \mathrm{~m}$ & N56-N60E/subv. \\
\hline CB-1 & LAMPRÓFIRO & & N45W \\
\hline CB-2 & LAMPRÓFIRO & $70 \mathrm{~cm}$ & N65E \\
\hline CB-3 & LAMPRÓFIRO & $1,7 \mathrm{~m}$ & $\mathrm{~N} 45 \mathrm{E} / 65 \mathrm{NW}$ \\
\hline CB-4-A & LAMPRÓFIRO & $1 \mathrm{~m}$ & N65E/subv. \\
\hline CB-4-B & LAMPRÓFIRO & $6 \mathrm{~cm}$ & N55E/subv. \\
\hline CB-5 & BASALTO & $1 \mathrm{~m}$ & N47E/subv. \\
\hline CB-6 & BASALTO & $5 \mathrm{~m}$ & N45E/subv. \\
\hline CB-7-1 & LAMPRÓFIRO & $90 \mathrm{~cm}$ & N40E/subv. \\
\hline CB-7-2 & LAMPRÓFIRO & $90 \mathrm{~cm}$ & N40E/subv. \\
\hline CB-8A & LAMPRÓFIRO & $40 \mathrm{~cm}$ & $\mathrm{~N} 30 \mathrm{E} /$ subv. \\
\hline CB-8B/C & LAMPRÓFIRO & $1 \mathrm{~m}$ & N30E/subv. \\
\hline CB-9 & LAMPRÓFIRO & $1,5 \mathrm{~m}$ & $\mathrm{~N} 30 \mathrm{E} /$ subv. \\
\hline CB-10 & LAMPRÓFIRO & $2 \mathrm{~m}$ & N40E/subv. \\
\hline CB-11 & BASALTO & $1,5 \mathrm{~m}$ & $\mathrm{~N} 40 \mathrm{E} /$ subv. \\
\hline CB-12 & LAMPRÓFIRO & $15 \mathrm{~cm}$ & N37E/subv. \\
\hline \multicolumn{4}{|c|}{ CB-13 (observado) } \\
\hline \multicolumn{4}{|c|}{ CB-14 (observado) } \\
\hline CB-15 & TRAQUITO & $1,50-2 \mathrm{~m}$ & $\mathrm{~N} 36 \mathrm{E} / 30 \mathrm{NW}$ \\
\hline CB-16 & LAMPRÓFIRO & $2,50-3 \mathrm{~m}$ & $\mathrm{~N} 56 \mathrm{E} / 80 \mathrm{NW}$ \\
\hline \multicolumn{4}{|l|}{ Ponta do Recife } \\
\hline PP-1 & BASALTO & $50 \mathrm{~cm}$ & N75E/subv. \\
\hline PP-2 & BASALTO & $5 \mathrm{~cm}$ & N52E/subv. \\
\hline PP-3 & BASALTO & $70 \mathrm{~cm}$ & $\mathrm{~N} 30 \mathrm{E} /$ subv. \\
\hline PP-4-1 & BASALTO & & NIOE/subv. \\
\hline PP-4-2 & BASALTO & $40 \mathrm{~cm}$ & N54E/subv. \\
\hline PP-4-3 & BASALTO & $30 \mathrm{~cm}$ & N55E/subv. \\
\hline \multicolumn{4}{|l|}{ Ponta do Araçá } \\
\hline PA-1 & LAMPRÓFIRO & $90 \mathrm{~cm}$ & $\mathrm{~N} 34 \mathrm{E} / 45 \mathrm{NW}$ \\
\hline PA-2 & BASALTO & $70 \mathrm{~cm}$ & N45E/subv. \\
\hline PA-3 & BASALTO & $1,2 \mathrm{~m}$ & N40E/subv. \\
\hline $\mathrm{PA}-4$ & LAMPRÓFIRO & $70 \mathrm{~cm}$ & N75E/subv. \\
\hline PA-5 & LAMPRÓFIRO & $50 \mathrm{~cm}$ & $65 \mathrm{E} / 40 \mathrm{NW}-\mathrm{N} 20 \mathrm{E} / \mathrm{subv}$ \\
\hline PA-6 & BASALTO & $9 \mathrm{~cm}$ & $\mathrm{~N} 25 \mathrm{E} /$ vert. \\
\hline PA-7-I & BASALTO & $90 \mathrm{~cm}$ & N55E/subv. \\
\hline PA-7-01-A & LAMPRÓFIRO & $60 \mathrm{~cm}$ & N55E/subv. \\
\hline
\end{tabular}

Tab.1 - 1 
TABELA 1 - Relação dos diques representados na FIGURA 1.

\begin{tabular}{|c|c|c|c|}
\hline PONTO & DESCRIÇÃO DE CAMPO & ESPESSURA & ATITUDE \\
\hline \multicolumn{4}{|c|}{ Ponta do Araçá (cont.) } \\
\hline PA-8A & LAMPRÓFIRO & $25 \mathrm{~cm}$ & N50E \\
\hline PA-8B & BASALTO & $40 \mathrm{~cm}$ & N36E-N20E/subv. \\
\hline PA-8C & LAMPRÓFIRO & & N45-55E/subv. \\
\hline PA-8D & LAMPRÓFIRO & $30 \mathrm{~cm}$ & N45E-N23E/subv. \\
\hline PA-8E & BASALTO? & $30 \mathrm{~cm}$ & NE - irregular \\
\hline PA-9 & LAMPRÓFIRO & $60 \mathrm{~cm}$ & N65E/subv. \\
\hline PA-10 & LAMPRÓFIRO & $15 \mathrm{~cm}$ & N47E/subv. \\
\hline PA-11 & LAMPRÓFIRO & $70 \mathrm{~cm}$ & $\mathrm{~N} 60 \mathrm{E} / \mathrm{v}$ \\
\hline PA-11B & LAMPRÓFIRO & & $\mathrm{N} 60 \mathrm{E} /$ subv. \\
\hline PA-12 & LAMPRÓFIRO & $20 \mathrm{~cm}$ & N35E/subv. \\
\hline PA-13 & LAMPRÓFIRO & $20-30 \mathrm{~cm}$ & N25E/subv. \\
\hline PA-14-1 & LAMPRÓFIRO & $30 \mathrm{~cm}$ & N27E/subv. \\
\hline PA-14-2 & LAMPRÓFIRO & & $\mathrm{N} 40 \mathrm{E} /$ subv. \\
\hline PA-15 & LAMPRÓFIRO & $30 \mathrm{~cm}$ & N35E \\
\hline PA-16 & BASALTO? & $1 \mathrm{~m}$ & N40E-N70E \\
\hline PA-16B & BASALTO & & $\mathrm{N}-\mathrm{S} / 34 \mathrm{~W}$ \\
\hline PA-17 & BASALTO & $2 \mathrm{~m}$ & N25E/subv. \\
\hline PA-18 (blocos) & LAMPRÓFIRO & & \\
\hline \multicolumn{4}{|c|}{ Iha de São Sebastião } \\
\hline \multicolumn{4}{|c|}{ Portinho à Praia do Veloso } \\
\hline IB-1 & BASALTO & & N-S \\
\hline IB-2 & BASALTO & $50 \mathrm{~cm}$ & N44E \\
\hline IB-3 & BASALTO & & N38E/80SE \\
\hline IB-4 & BASALTO & $1 \mathrm{~m}$ & $\mathrm{~N} 46 \mathrm{E} / 85 \mathrm{SE}$ \\
\hline IB-5 & BASALTO & & N08E/85SE \\
\hline IB-6 (blocos) & BASALTO & & \\
\hline IB-7 & BASALTO & $40 \mathrm{~cm}$ & N40E/vert. \\
\hline IB-8 & ALCALINA & $68 \mathrm{~cm}$ & N50E/80SE \\
\hline IB-9 & & $10 \mathrm{~cm}$ & N40E/vert. \\
\hline IB-11 & ALCALINA & $20-30 \mathrm{~cm}$ & N62E \\
\hline IB-12 & & $1 \mathrm{~m}$ & $\mathrm{~N} 66 \mathrm{E} / 65 \mathrm{NW}$ \\
\hline \multicolumn{4}{|c|}{ Ponta da Armação } \\
\hline IB-10 (blocos) & ALCALINA & & \\
\hline \multicolumn{4}{|l|}{ Ponta Larga } \\
\hline IB-17-I & TRAQUTTO & $1,8 \mathrm{~m}$ & N46E/70SE \\
\hline IB-15-IV & TRAQUITO & $15 \mathrm{~cm}$ & N68E/85SE \\
\hline IB-17-VII & TEFRITO & $1 \mathrm{~m}$ & N80E/85SE \\
\hline IB-17-X & TEFRITO & $30 \mathrm{~cm}$ & N50E/subv. \\
\hline \multicolumn{4}{|l|}{ Praia do Bonete } \\
\hline IB-13 (blocos) & BASALTO & & \\
\hline IB-14A & BASALTO? & $2 \mathrm{~m}$ & $\mathrm{~N} 45 \mathrm{E} / 52 \mathrm{SE}$ \\
\hline IB-14B & ALCALINA? & & N40E/60SE \\
\hline IB-14C & BASALTO & $30 \mathrm{~cm}$ & N82E/65SE \\
\hline IB-15A & BASALTO? & $81 \mathrm{~cm}$ & N88E/75SE \\
\hline IB-15B & $?$ & & N82E/subv. \\
\hline IB-16 & TRAQUITO & & \\
\hline
\end{tabular}




\section{AS ROCHAS ALCALINAS DA ILHA DE SÃO SEBASTIÃO}

BELLIENI et al. (1990) apresentam 13 análises químicas de rocha total por fluorescência de raios $\mathrm{X}$ de três dos quatro stocks alcalinos da Ilha de São Sebastião, denominados por HENNIES \& HASUI (1977) de Serraria, Mirante, São Sebastião e Canas (FIGURA 1). Esses stocks mostram uma distribuição de tipos litológicos que tende desde termos mais ácidos (com quartzo) na periferia até intermediários no centro. Os primeiros são representados por nordmarkitos, aos quais se associam algumas zonas essexíticas. Adentrando os maciços, são encontradas rochas sieníticas, mais claras, com raro quartzo e biotita relativamente mais abundante. O núcleo do stock do Mirante é constituído de sienitos nefelínicos. Blocos destas rochas também ocorrem no stock da Serraria.

Um pequeno corpo de rochas básico-alcalinas foi denominado de stock de Canas. Seus limites se acham, na maior parte, cobertos por blocos rolados dele derivados, desde ijolitos até gabros nefelínicos. SILVA et al. (1977) descrevem o teralito da Ponta das Canas como uma rocha de textura marcante, composta de grandes cristais de titanoaugita e olivina com até $2,5 \mathrm{~cm}$ em matriz com feldspatos (labradorita) e feldspatóides (nefelina), apatita e magnetita. HENNIES \& HASUI (1968) consideram que a intrusão do stock deu-se acompanhando ou seguindo a dos três stocks maiores.

Os tipos hipabissais, de expressão bem menor, são bostonitos, microfoiaítos, sodalita microfoiaítos, microteralitos e aplitos de nefelina sienito.

As variedades com textura porfirítica são sodalita fonólitos e sodalita traquitos. Os diques alcalinos finais têm portes e aspectos variados. Podem aparecer como delicados veios ou corpos tabulares de alguns metros. Às vezes mostram aspecto vítreo e alguns são aparentemente múltiplos.

Outros pormenores sobre a geologia e petrologia da Ilha de São Sebastião podem ser encontrados em FREITAS (1947).

\section{OS DIQUES BÁSICOS E ULTRABÁSICOS}

Ao longo dos costões entre a Ponta do Itapuã e Ponta do Araçá (Município de São Sebastião), os diques apresentam-se muito pouco ou não alterados e aparecem formando pequenos enxames de seis ou mais diques que cortam as pontas formadas por rochas do Complexo Costeiro e que separam as praias do
Guaecá, Baraqueçaba, Cabelo Gordo, Grande, Barra Limpa e Pernambuco. Na Ilha de São Sebastião, os diques estão mais alterados e, em alguns casos, são encontrados blocos rolados de diferentes tamanhos e formas, ao longo de drenagens ou dos costões.

Apesar de sua granulação bastante fina, é possível distinguir-se macroscopicamente algumas das litologias.

Entre as rochas de composição básica predominam os diabásios, de textura em geral afanítica, coloração cinza-preta, por vezes levemente acastanhada (ferrugem). As bordas são geralmente muito finas e as espessuras dos diques variam desde centimétricos a métricos. Aparecem quase sempre fraturados, provavelmente resultado do resfriamento.

Os lamprófiros são geralmente porfiríticos, com fenocristais raramente ultrapassando $1 \mathrm{~cm} \mathrm{e}$ aparecendo em proporções muito variadas. A densidade e o tamanho dos fenocristais podem diminuir do centro para as bordas dos diques. Estruturas globulares milimétricas preenchidas por calcita são às vezes visíveis, contrastando com a coloração da rocha que é cinza escuro a preto. Apresentam aspecto "poroso", devido à lixiviação de glóbulos ou de fenocristais. As espessuras restringem-se ao intervalo $30-40 \mathrm{~cm}$ a $1-1,5 \mathrm{~m}$.

\subsection{Pontas do Guaecá e Baraqueçaba}

Na FIGURA 1 os diques encaixados nas pontas do Guaecá e do Baraqueçaba estão assinalados com as siglas PG e PB, respectivamente.

Na Ponta do Guaecá, uma seqüência de lamprófiros de direção predominante $\mathrm{N} 50^{\circ} \mathrm{E}$ e mergulho praticamente vertical encaixa-se em migmatitos anatexíticos de coloração rosada do Complexo Costeiro.

Os lamprófiros da Ponta do Baraqueçaba têm a mesma direção e aparentemente a mesma composição daqueles da Ponta do Guaecá. Destaca-se neste conjunto um sill de rocha básica afanítica (que não será abordado aqui), encaixado nos migmatitos anatexíticos.

\subsection{Ponta do Baraqueçaba à Ponta do Araçá}

Na FIGURA 1 os diques que cortam o costão entre a Ponta do Baraqueçaba e a do Baleeiro e a Ponta do Recife e a do Araçá estão assinalados com as siglas CB (Cabelo Gordo), PP (Barra Limpa) e PA (Araçá).

Num corte da SP-55, próximo das torres de água da SABESP e da Praia do Baraqueçaba, ocorre um dique alterado de traquito (CB-15, 
FOTO 1), de direção $\mathrm{N} 46^{\circ} \mathrm{E}$ e mergulho $30^{\circ} \mathrm{NW}$, de coloração levemente arroxeada, com fenocristais de feldspato que são desde milimétricos, junto às bordas, a centimétricos, formando aglomerados nas porções mais centrais. COUTINHO (1966) já havia assinalado que entre as praias do Cabelo Gordo e Segredo e as de Baraqueçaba e Guaecá ocorrem sills sub-horizontais de rocha traquítica, sendo que na primeira ocorrência são distintos dois sills de 1,5 e $2,5 \mathrm{~m}$ de espessura e na segunda, num morro de $50 \mathrm{~m}$ de altura, superpõem-se quatro sills, sendo inferior duplo e tendo cada um aproximadamente $2 \mathrm{~m}$ de espessura. Esses traquitos cortam diques de diabásio e piroxênio lamprófiros.

Pela composição e textura, aquele autor os classifica como quartzo bostonitos e são rochas que se assemelham aos sienitos e nordmarkitos da Ilha de São Sebastião. O autor conclui que os sills são os correspondentes hipabissais desses magmas, ocorrendo sob a forma de cone-sheets no continente.

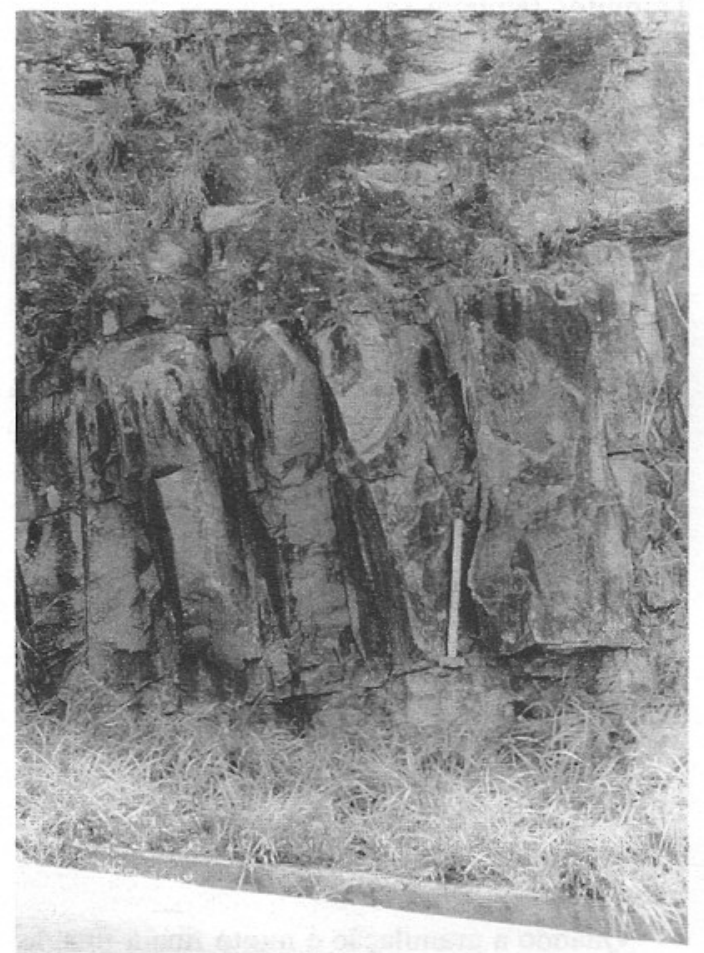

FOTO 1 - Dique alterado de traquito (CB-15), de direção $\mathrm{N} 46^{\circ} \mathrm{E}$, mergulho $30^{\circ} \mathrm{NW}$ e $1-2 \mathrm{~m}$ de espessura. Corte da SP-55, próximo à Praia do Baraqueçaba.

Próximo do ponto CB-15 aflora um lamprófiro de aspecto alterado, de direção $\mathrm{N} 56^{\circ} \mathrm{E}$, apresentando no contato com a encaixante estruturas de fluxo e, na porção mais central, olivinas cen- timétricas abundantes em matriz afanítica. Este corpo tem continuidade com os da Praia do Cabelo Gordo, onde uma seqüência de diques pode ser acompanhada por aproximadamente $1 \mathrm{~km}$, encaixados em migmatito bastante heterogêneo, com porções estromáticas e anatexíticas. Os diques apresentam espessuras variadas e direção praticamente paralela à costa $\left(\mathrm{N} 30^{\circ}-65^{\circ} \mathrm{E}\right)$. Dentre esses, predominam lamprófiros com abundantes fenocristais submilimétricos. Os diques podem apresentar feições de alteração semelhantes à esfoliação esferoidal. No meio dessa seqüência de lamprófiros foram encontrados alguns diques básicos. Um deles (CB-6), com 5m de espessura aparente e subvertical, apresenta-se ramificado e encaixado numa porção mais predominantemente estromática do migmatito heterogêneo cinza-claro.

$\mathrm{Na}$ Ponta do Araçá, outra seqüência de diques corta migmatitos estromáticos que passam rapidamente para porções graníticas, cortadas por veios pegmatíticos e de quartzo. Os diques não são retilíneos e às vezes estão interrompidos ou se ramificam. As direções variam entre N-S e $\mathrm{N} 75^{\circ} \mathrm{E}$. As exposições estendem-se ao longo de $800 \mathrm{~m}$ de costa, sendo que, além de diques, blocos rolados, apresentando níveis cumuláticos muito ricos em olivina, aparecem no costão próximo à Praia Barra Limpa. Com os lamprófiros alternam-se alguns diques básicos. No ponto PA-7, um dique básico segue paralelamente a um dique de lamprófiro com direção $\mathrm{N} 55^{\circ} \mathrm{E}$ (FOTO 2). Nos contatos entre os diques e com a encaixante são observadas feições muito semelhantes a diques mais finos, de espessura muito irregular, de coloração mais clara.

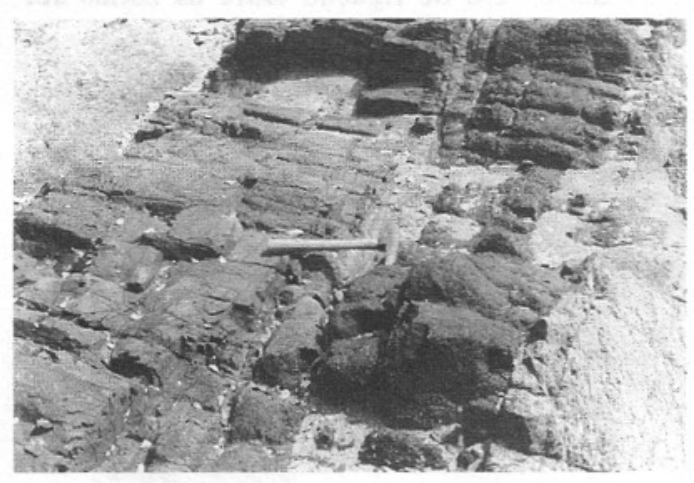

FOTO 2 - No ponto PA-7, um dique de diabásio de $80 \mathrm{~cm}$ de espessura trazendo xenólitos da encaixante segue paralelamente a um dique de lamprófiro de $60 \mathrm{~cm}$ de espessura, encaixados em gnaisse granítico. Ponta do Araçá.

\subsection{Ilha de São Sebastião}

Na FIGURA 1 esses diques estão assinalados com a sigla IB. Observa-se que os aflo- 
ramentos amostrados podem coincidir com os de BELLIENI et al. (1990).

$\mathrm{Na}$ Praia da Armação, $4 \mathrm{~km}$ a norte da cidade de Ilhabela, espalham-se blocos de litologias variadas, inclusive das rochas alcalinas da ilha. No ponto IB-10 são encontrados blocos mostrando um dique fino cortando a rocha alcalina (FOTO 3).

Desde Portinho até a Praia do Veloso observa-se uma série de diques de direção NS-N $50^{\circ} \mathrm{E}$ que afloram principalmente nos barrancos da estrada que segue paralela ao Canal de São Sebastião. Os diques encontram-se, em geral, alterados. SILVA et al. (1977) descrevem, ao lado do trapiche do ferryboat, a ocorrência de um grande dique de andesito pórfiro (FREITAS, 1976), que se estende para a Ponta da Sela a SW e é truncado pelo Maciço Alcalino da Serraria, a N-NE. A ocorrência da Ponta das Furnas, orla norte da ilha, poderia constituir seu prolongamento NE. Segundo HENNIES \& HASUI (1977), a melhor exposição se vê no corte da estrada que vai de Ilhabela para SW, próximo à Barra Velha. O dique apresenta disjunção colunar normal às paredes e são vistos xenólitos de microclínio e fragmentos da encaixante. Outros diques existem, paralelos aos citados, com orientação NE, mas de menor extensão, tendo sido observados na zona central da ilha e na região centro-sul. Os autores constatam, também, que os grandes diques básicos se refletem no relevo, constituindo cristas lineares ou linhas de morros de direção NE. As mais salientes estão na região central da ilha, onde constituem verdadeiro "elo de ligação entre as zonas acidentadas do SW e NE da ilha".

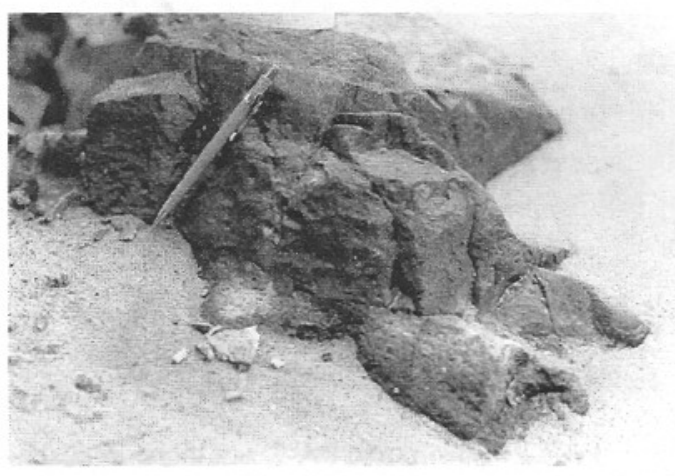

FOTO 3 - No ponto IB-10 são encontrados blocos mostrando um dique fino cortando o nordmarkito. Ponta da Armação. Ilha de São Sebastião.

Uma seqüência de diques ocorre em Ponta Larga, próximo a Borrifos, encaixados tanto no gnaisse granítico do Complexo Costeiro, como na rocha alcalina (stock de São Sebastião). A
NW de um pequeno lago, um extenso dique de traquito, com microfenocristais de feldspato e biotita, de espessura variável chegando a $1,80 \mathrm{~m}$ e ramificado, atravessa ambas litologias.

Entretanto, diques mais finos, com outra composição (ver Geoquímica), apenas cortam o gnaisse granítico, sendo truncados pela rocha alcalina. A SE xenólitos de diques de mesma natureza (FOTO 4) são encontrados próximos ao contato das encaixantes que é, por sua vez, bastante difuso.

$\mathrm{Na}$ Praia do Bonete, no sul da ilha, uma série de diques corta a rocha encaixante, que é um gnaisse granítico de granulação médiagrossa, semelhante ao de Ponta Larga, com abundantes fenocristais centimétricos de feldspato. A encaixante é atravessada por níveis de anfibolito, que podem ou não acompanhar a foliação. Os diques, em certos locais, entrecortam-se e estão encaixados nas fraturas do gnaisse. Entre diques máficos e diques mais finos de aspecto vítreo foi encontrada uma variedade com características mais intermediárias. Traquitos também são encontrados próximo à Ponta das Enchovas.

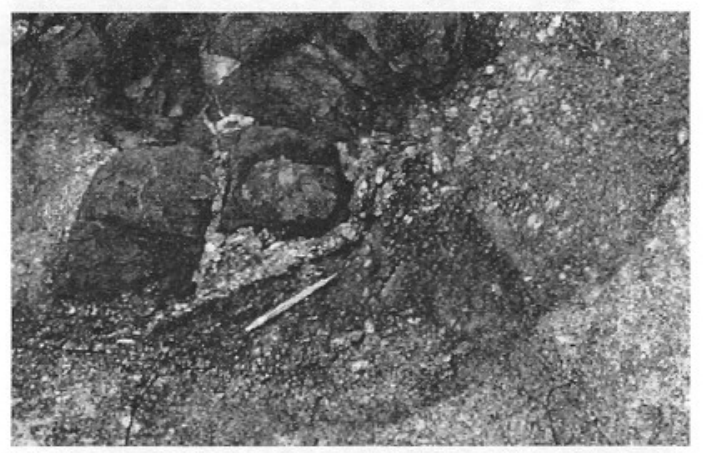

FOTO 4 - Xenólitos de diques de tefrito na rocha alcalina (IB-17). Ponta Larga. Ilha de São Sebastião.

\section{PETROGRAFIA DOS DIQUES}

Entre as rochas de composição básica (diabásios) encontram-se tipos afaníticos e muito finos a finos.

Quando a granulação é muito fina a fina, as texturas predominantes são a intergranular, a ofítica/subofitica e, localmente, a intersertal (FOTO 5). A matriz é dominada por feldspato de hábito ripiforme, clinopiroxênio castanho de hábito granular e vidro. Biotita pode aparecer associada ao piroxênio ou a minerais opacos. Esses últimos são predominantemente ilmenita $\mathrm{e}$ titanomagnetita e apresentam, em geral, textura dendrítica ou esquelética. Pirita é mais rara, constituindo cristais cúbicos muito pequenos, 
disseminados. Os minerais secundários mais freqüentes são sericita e clorita, que aparecem como manchas irregulares.

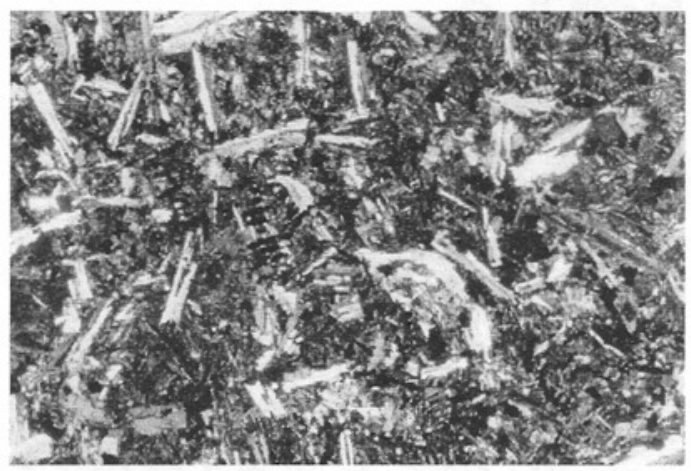

FOTO 5 - Textura intersertal do basalto PA-7I, com ripas de feldspato em malha formada por piroxênio granular e vidro. Podem aparecer fenocristais mal formados de feldspato. Os minerais opacos apresentam-se ou esqueléticos ou cúbicos. Nicóis cruzados. Lado maior da foto: $4,2 \mathrm{~mm}$.

Os lamprófiros distinguem-se dos diabásios pela predominância de piroxênio sobre feldspato e pela abundância de fenocristais de minerais máficos, principalmente piroxênio e olivina. Os lamprófiros podem ser subdivididos em: camptonitos, monchiquitos e lamprófiros picríticos. Os monchiquitos apresentam, além da mineralogia dos camptonitos, analcima e vidro (FOTO 6).

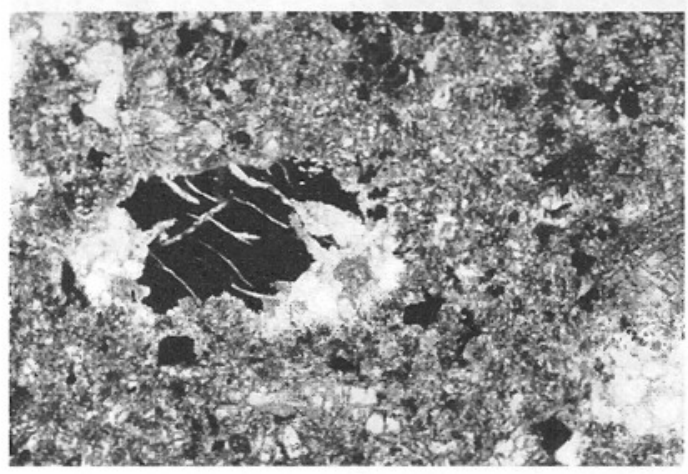

FOTO 6 - Estrutura globular em monchiquito (PG-1-5) preenchida por analcima (isótropa) e carbonato. Nicóis cruzados. Lado maior da foto: $2,5 \mathrm{~mm}$.

A kaersutita é característica dos lamprófiros e encontra-se em quantidades variáveis principalmente nos camptonitos e monchiquitos. Destaca-se das porções félsicas da matriz dos camptonitos pela sua coloração marrom e bordas esverdeadas (FOTO 7). Nessas porções também se distinguem biotitas verdes muito finas.

Em geral, olivina está completamente pseudomorfizada (carbonato e clorita - FOTO 7), podendo atingir $4 \mathrm{~mm}$ de maior dimensão. A matriz (fanerítica fina) é dominada por titanaugita, usualmente com kaersutita associada. Feldspato aparece como ripas, mesclado com o material intersticial de birrefringência muito baixa. Os cromoespinélios distinguem-se pela coloração castanha escura e bordas opacas (ferricromitas) e acham-se incluídos nas olivinas ou dispersos na matriz. Os outros minerais opacos assumem formas dendríticas, aciculares ou irregulares.

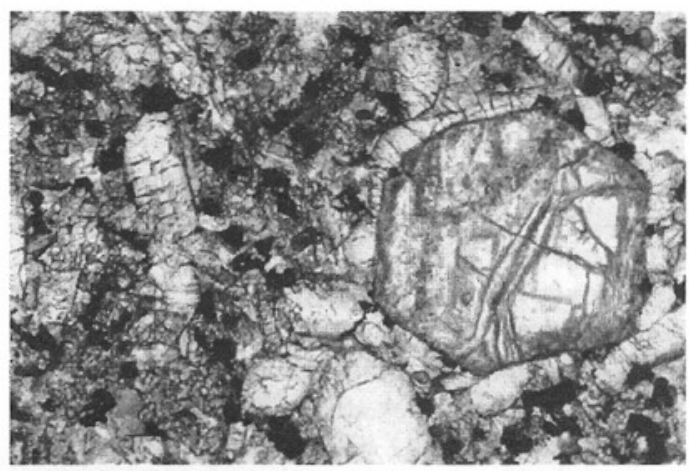

FOTO 7 - Monchiquito (PG-1-6A) apresentando fenocristal milimétrico de olivina em matriz formada por piroxênio augítico, kaersutita, porções félsicas e minerais opacos. Nicóis paralelos. Lado maior da foto: $2,5 \mathrm{~cm}$.

Os diques da Ponta do Guaecá são monchiquitos em que os aglomerados de fenocristais de piroxênio chegam a atingir $1 \mathrm{~mm}$ de diâmetro. Em função da quantidade desses aglomerados, a textura da rocha pode tornar-se glomeroporfirítica. Os fenocristais de piroxênio, quando isolados, atingem até $4 \mathrm{~mm}$ de maior dimensão. São zonados, com bordas mais escuras. Podem apresentar inclusões de olivina pseudomorfizada. A matriz é formada por aglomerados de piroxênio augítico, em cujos interstícios aparecem feldspato alcalino, analcima, kaersutita e massa alterada. As porções félsicas são constituídas por plagioclásio ripiforme e acicular em arranjo com kaersutita. Os minerais opacos apresentam formas esqueléticas. Carbonato pode aparecer disperso na matriz. Analcima é abundante (15\%), de hábito arredondado ou mais irregular, chegando a $1,5 \mathrm{~mm}$ de diâmetro. As bordas são marcadas por inclusões muito finas de kaersutita. As estruturas globulares podem ser constituídas por combinações de analcima, carbonato e clorita, assim como feldspato alcalino.

Às vezes, a classificação de uma rocha lamprofírica não é simples, por não existirem critérios absolutos para sua caracterização, como é o caso dos diques que ocorrem na Ponta do Araçá. Vários apresentam características mistas entre camptonitos e lamprófiros picríti- 
cos. Foram denominadas de lamprófiros picríti$\cos$ as rochas muito ricas em megacristais de olivina. Kaersutita, biotita e analcima são mais raras ou ausentes nessas rochas. A matriz é composta predominantemente por piroxênio, contendo, em certos casos, feldspato. Megacristais de olivina podem estar associados aos de piroxênio. Cromoespinélio é encontrado não somente incluso em olivina, como também disseminado na matriz. As olivinas podem estar parcialmente frescas, como aquelas das bordas do lamprófiro PA-8C, sendo compostas por mais de $80 \%$ de forsterita (GARDA, 1995).

Os basaltos alcalinos (ou álcali basaltos) ora apresentam texturas muito semelhantes à dos diabásios, ora às dos lamprófiros. Sua matriz é formada por augita castanha e ripas de feldspato e por quantidades variáveis de microfenocristais de piroxênio e plagioclásio, também ocorrendo formas regulares, normalmente associadas a minerais opacos, sugerindo ser alteração completa de olivina. Outra variedade é a encontrada em Ponta Larga (FOTO 8), sendo que, na matriz, aparece kaersutita, provavelmente substituindo piroxênio, junto com ripas de plagioclásio cálcico. Carbonato, aparentemente secundário, ocorre com freqüência. Biotita também pode se apresentar em proporções variáveis.

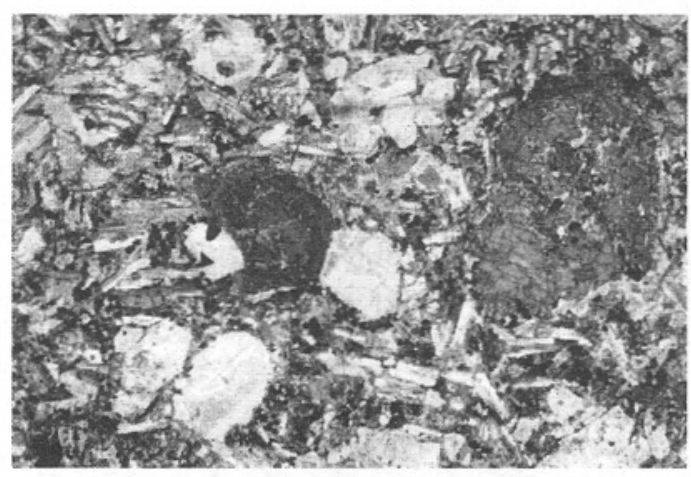

FOTO 8 - Tefrito (IB-17-V) constituído por fenocristais de piroxênio e feldspato e matriz formada por ripas de plagioclásio, kaersutita (provalvelmente substituindo piroxênio), biotita e opacos. Carbonato é relativamente abundante. Nicóis cruzados. Lado maior da foto: $1 \mathrm{~cm}$.

O dique de rocha ultrabásica (microteralito) da Ponta da Armação (IB-10(e)) possui matriz formada por plagioclásios tabulares e piroxênios abundantes. O feldspato pode aparecer como fenocristal, juntamente com piroxênio (FOTO 9).

Os traquitos são rochas porfiríticas, com fenocristais de plagioclásio e sanidina e matriz fina constituída por feldspato alcalino e raros minerais opacos. Às vezes contêm biotita (FOTO 10).

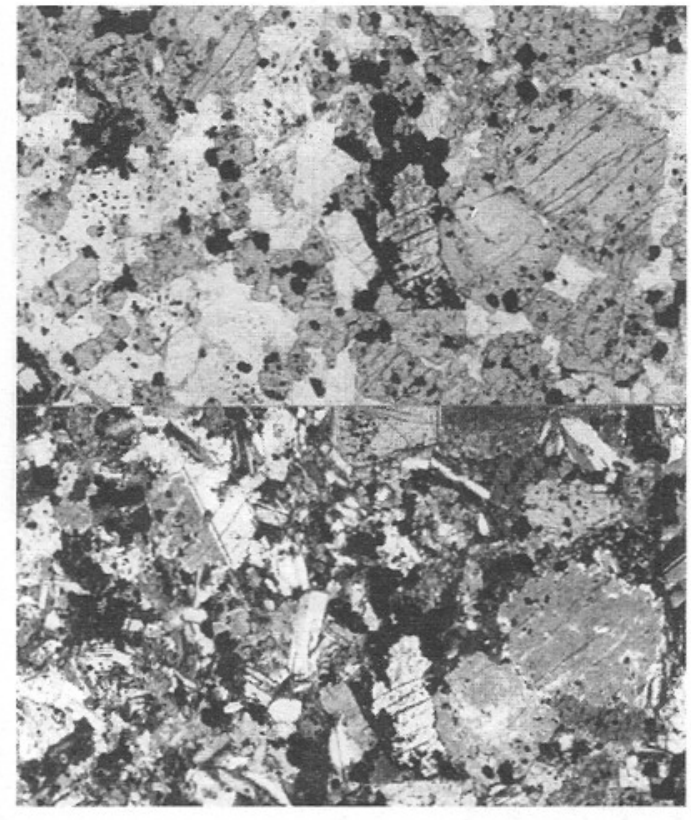

FOTO 9 - Microteralito (IB-10(e)) formado predominantemente por piroxênio, feldspato, fóides e minerais opacos. Nicóis paralelos e cruzados (respectivamente porções superior e inferior da foto). Largura da foto: $2,09 \mathrm{~mm}$.

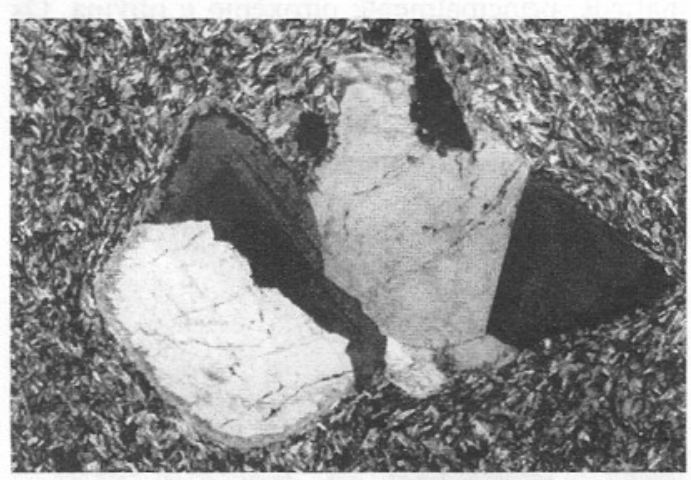

FOTO 10 - Traquito (IB-16-2) constituído predominantemente por feldspato, tanto formando a matriz (que também pode conter biotita), como os fenocristais. Nicóis cruzados. Lado maior da foto: $4 \mathrm{~mm}$.

\section{GEOQUÍMICA}

\subsection{Elementos maiores}

As composições químicas de 59 amostras analisadas por fluorescência de raios X estão listadas na TABELA 2. A presença de glóbulos preenchidos por carbonato, olivina pseudomorfizada e de minerais hidratados como kaersutita, mica e analcima faz com que a perda ao fogo seja elevada nos lamprófiros picríticos, monchiquitos e camptonitos. Optou-se, então, por não se recalcular as análises para base anidra, como uma forma de se levar esse fato em conta. 
TABELA 2 - Composições de rocha total, obtidas por fluorescència de raios X, dos diques assinalados na FIGURA 1. n.d. = não determinado; $\mathrm{Mg} \#=100 \mathrm{x} \mathrm{MgO}$ molar/(FeOt molar + $\mathrm{MgO}$ molar).

\begin{tabular}{|c|c|c|c|c|c|c|c|c|c|c|c|c|c|c|c|}
\hline Amostra & PG-1-1 & PG-1-5 & PG-1-6A & PG-3-2 & PG-3-4 & PB-2-1 & PB-5-2 & PB-5-3 & CB-7-2B & CB-7-2C & CB-9-2 & CB-10-2 & CB-11-2 & CB-16 & PP-3-3 \\
\hline Rocha & F-monch & F-monch & F-monch & F-monch & F/Pc-campto & TEPH & TEPH & TEPH & F-campto & F-campto & $\mathrm{Pc}$ & TEPH & BAS & Pc-lpicr & F-monch \\
\hline$\overline{\mathrm{SiO} 2}$ & 39.61 & 38.09 & 40.62 & 40.41 & 41.02 & 43.55 & 43.10 & 43.74 & 37.60 & 38.05 & 44.31 & 43.72 & 47.87 & 44.68 & 35.87 \\
\hline $\mathrm{TiO} 2$ & 2.67 & 2.25 & 2.37 & 2.02 & 2.11 & 2.58 & 2.68 & 2.73 & 2.12 & 2.04 & 1.21 & 2.21 & 3.68 & 1.97 & 1.78 \\
\hline $\mathrm{Al} 2 \mathrm{O} 3$ & 10.88 & 8.54 & 10.38 & 9.78 & 12.02 & 16.24 & 16.46 & 16.82 & 12.42 & 12.15 & 8.52 & 13.06 & 13.05 & 9.86 & 12.70 \\
\hline $\mathrm{FeOt}$ & 11.17 & 10.20 & 11.00 & 10.04 & 10.51 & 11.69 & 11.76 & 11.75 & 10.90 & 10.88 & 7.15 & 10.36 & 15.29 & 9.74 & 10.57 \\
\hline $\mathrm{MnO}$ & 0.13 & 0.17 & 0.15 & 0.14 & 0.16 & 0.20 & 0.20 & 0.22 & 0.19 & 0.19 & 0.11 & 0.18 & 0.19 & 0.15 & 0.22 \\
\hline $\mathrm{MgO}$ & 10.09 & 12.00 & 11.63 & 13.42 & 10.56 & 5.03 & 4.67 & 4.45 & 8.54 & 8.96 & 14.21 & 8.81 & 4.61 & 12.78 & 7.92 \\
\hline $\mathrm{CaO}$ & 16.16 & 16.20 & 15.79 & 14.49 & 13.87 & 10.58 & 9.70 & 9.06 & 14.44 & 15.15 & 15.50 & 12.74 & 7.99 & 15.89 & 13.40 \\
\hline $\mathrm{Na} 2 \mathrm{O}$ & 1.15 & 0.54 & 1.06 & 0.68 & 1.23 & 2.89 & 2.86 & 3.39 & 1.91 & 1.33 & 0.62 & 2.05 & 2.58 & 1.90 & 2.19 \\
\hline $\mathrm{K} 2 \mathrm{O}$ & 1.15 & 0.88 & 0.93 & 1.01 & 1.54 & 2.27 & 2.71 & 2.13 & 1.66 & 1.72 & 0.90 & 1.60 & 1.48 & 0.50 & 1.33 \\
\hline P2O5 & 0.29 & 0.21 & 0.31 & 0.22 & 0.35 & 0.53 & 0.52 & 0.60 & 1.38 & 1.23 & 0.20 & 0.37 & 0.54 & 0.44 & 1.15 \\
\hline Total & 93.30 & 89.08 & 94.24 & 92.21 & 93.37 & 95.56 & 94.66 & 94.89 & 91.16 & 91.70 & 92.73 & 95.10 & 97.28 & 97.91 & 87.13 \\
\hline P.Fogo & 5.31 & 10.46 & 4.16 & 5.90 & 5.14 & 2.86 & 3.75 & 3.79 & 8.57 & 6.41 & 5.87 & 3.56 & 2.02 & 0.89 & 13.37 \\
\hline Total & 98.61 & 99.54 & 98.40 & 98.11 & 98.51 & 98.42 & 98.41 & 98.68 & 99.73 & 98.11 & 98.60 & 98.66 & 99.30 & 98.80 & 100.50 \\
\hline $\mathrm{Mg} \#$ & 61.67 & 67.71 & 65.33 & 70.43 & 64.15 & 43.39 & 41.43 & 40.29 & 58.27 & 59.48 & 77.98 & 60.25 & 34.95 & 70.05 & 57.17 \\
\hline $\mathrm{Cr}$ & 227 & 580 & 386 & 886 & 584 & 44 & 49 & 50 & 134 & 262 & 1823 & 387 & 31 & 665 & 76 \\
\hline $\mathrm{Ni}$ & 209 & 278 & 207 & 311 & 214 & 64 & 16 & 32 & 140 & 179 & 411 & 150 & 57 & 261 & 131 \\
\hline Co & 106 & 95 & 88 & 67 & 84 & 52 & 28 & 29 & 78 & 68 & 103 & 63 & 30 & 60 & 44 \\
\hline V & 306 & 312 & 315 & 297 & 266 & 208 & 190 & 182 & 213 & 216 & 222 & 258 & 424 & 300 & 171 \\
\hline $\mathrm{Cu}$ & 340 & 313 & 155 & 119 & 120 & 132 & 16 & 23 & 133 & 116 & 100 & 121 & 173 & 96 & 120 \\
\hline $\mathrm{Zn}$ & 58 & 47 & 61 & 52 & 67 & 104 & 88 & 98 & 85 & 80 & 47 & 73 & 132 & 67 & 52 \\
\hline S & 240 & 240 & 200 & 160 & 200 & 160 & 240 & 240 & 240 & 200 & 120 & 80 & 200 & n.d. & 160 \\
\hline $\mathrm{Rb}$ & 23 & 21 & 19 & 21 & 35 & 43 & 67 & 41 & 40 & 42 & 29 & 44 & 23 & 18 & 30 \\
\hline $\mathrm{Ba}$ & 455 & 333 & 442 & 403 & 569 & 775 & 872 & 790 & 641 & 603 & 256 & 628 & 483 & 365 & 583 \\
\hline $\mathrm{Sr}$ & 548 & 439 & 408 & 466 & 743 & 938 & 1249 & 1390 & 1138 & 887 & 322 & 617 & 632 & 655 & 1154 \\
\hline $\mathrm{Nb}$ & 25 & 25 & 29 & 35 & 43 & 47 & 45 & 44 & 39 & 35 & 21 & 40 & 18 & 38 & 36 \\
\hline $\mathrm{Zr}$ & 192 & 154 & 163 & 148 & 173 & 261 & 232 & 243 & 279 & 265 & 117 & 209 & 248 & 146 & 236 \\
\hline Y & 31 & 31 & 28 & 28 & 27 & 25 & 25 & 20 & 47 & 45 & 35 & 35 & 28 & 20 & 42 \\
\hline Th & n.d. & nd. & n.d. & n.d. & n.d. & nd. & n.d. & n.d. & n.d. & n.d. & 1 & 4 & n.d. & 1 & n.d. \\
\hline $\mathrm{U}$ & 1 & 1 & n.d. & 2 & 4 & 1 & n.d. & 1 & n.d. & 1 & 2 & 6 & 2 & 1 & n.d. \\
\hline $\mathrm{La}$ & 10 & 22 & 3 & 3 & 16 & 26 & 24 & 20 & 57 & 45 & 3 & 10 & 27 & n.d. & 41 \\
\hline $\mathrm{Ce}$ & 80 & 58 & 65 & 59 & 70 & 119 & 84 & 114 & 170 & 183 & 58 & 86 & 85 & n.d. & 138 \\
\hline $\mathrm{Nd}$ & 29 & 22 & 31 & 31 & 28 & 52 & 45 & 53 & 64 & 70 & 29 & 38 & 35 & n.d. & 54 \\
\hline
\end{tabular}

Petrografia: campto $=$ camptonito; lpicr $=$ lamprófiro picrítico; monch $=$ monchiquito

Classificação pelo diagrama TAS: $\mathrm{BAS}=$ basalto; $\mathrm{F}=$ foidito; $\mathrm{Pc}=$ basalto picritico; $\mathrm{TAND}=$ traquiandesito; $\mathrm{TEPH}=$ tefrito; $\mathrm{TRC}=$ traquito.

Tab. 2 - 1 


\begin{tabular}{|c|c|c|c|c|c|c|c|c|c|c|c|c|c|}
\hline $\begin{array}{l}\text { Amostra } \\
\text { Rocha }\end{array}$ & $\begin{array}{l}\text { PA-1 } \\
\text { TEPH }\end{array}$ & $\begin{array}{c}\mathrm{PA}-1(2) \\
\mathrm{F}\end{array}$ & $\begin{array}{c}\text { PA-1-2E } \\
\text { TEPH }\end{array}$ & $\begin{array}{l}\text { PA-1a } \\
\text { TEPH }\end{array}$ & $\begin{array}{l}\text { PA-1b } \\
\text { TEPH }\end{array}$ & $\begin{array}{c}\text { PA-Id1 } \\
\text { TEPH }\end{array}$ & $\begin{array}{l}\text { PA-1e } \\
\text { TEPH }\end{array}$ & $\begin{array}{l}\text { PA-1f } \\
\text { TEPH }\end{array}$ & $\begin{array}{l}\text { PA-1g } \\
\text { TEPH }\end{array}$ & $\begin{array}{l}\text { PA-2 } \\
\text { TEPH }\end{array}$ & $\begin{array}{l}\text { PA-5 } \\
\text { F-lpicr }\end{array}$ & $\begin{array}{c}\text { PA-7-I } \\
\text { BAS }\end{array}$ & $\begin{array}{c}\text { PA-7-III } \\
\text { BAS }\end{array}$ \\
\hline $\mathrm{SiO} 2$ & 41.38 & 40.83 & 41.84 & 41.81 & 42.38 & 42.37 & 42.67 & 41.50 & 41.73 & 43.51 & 36.80 & 49.63 & 49.55 \\
\hline $\mathrm{TiO} 2$ & 2.92 & 3.22 & 2.85 & 2.87 & 2.87 & 2.87 & 2.88 & 2.86 & 2.93 & 2.24 & 1.98 & 3.35 & 3.37 \\
\hline $\mathrm{Al} 2 \mathrm{O}_{3}$ & 14.35 & 12.68 & 14.39 & 13.72 & 14.04 & 13.97 & 14.29 & 13.70 & 14.15 & 13.23 & 11.84 & 12.64 & 12.51 \\
\hline $\mathrm{FeOt}$ & 12.67 & 13.68 & 12.60 & 12.44 & 12.48 & 12.38 & 12.66 & 12.44 & 12.80 & 10.24 & 10.68 & 12.94 & 12.92 \\
\hline $\mathrm{MnO}$ & 0.19 & 0.18 & 0.18 & 0.19 & 0.20 & 0.19 & 0.19 & 0.20 & 0.20 & 0.13 & 0.19 & 0.18 & 0.19 \\
\hline $\mathrm{MgO}$ & 6.35 & 7.61 & 6.87 & 6.58 & 6.61 & 6.89 & 6.61 & 6.56 & 6.29 & 8.83 & 9.37 & 4.40 & 4.20 \\
\hline $\mathrm{CaO}$ & 12.46 & 13.83 & 13.09 & 12.98 & 13.12 & 13.29 & 12.70 & 12.76 & 12.66 & 12.05 & 16.41 & 7.95 & 7.77 \\
\hline $\mathrm{Na}_{2} \mathrm{O}$ & 1.38 & 1.20 & 1.37 & 1.50 & 1.42 & 1.42 & 1.35 & 1.62 & 1.42 & 1.47 & 1.31 & 2.62 & 2.73 \\
\hline $\mathrm{K} 2 \mathrm{O}$ & 2.57 & 1.98 & 2.05 & 2.48 & 2.20 & 2.06 & 2.42 & 2.53 & 2.78 & 2.61 & 1.53 & 1.54 & 1.60 \\
\hline $\mathrm{P} 205$ & 0.52 & 0.40 & 0.52 & 0.47 & 0.50 & 0.49 & 0.52 & 0.48 & 0.50 & 0.39 & 1.03 & 0.54 & 0.53 \\
\hline Total & 94.79 & 95.61 & 95.76 & 95.04 & 95.82 & 95.93 & 96.29 & 94.65 & 95.46 & 94.70 & 91.14 & 95.79 & 95.37 \\
\hline P.Fogo & 3.32 & 2.08 & 2.59 & 3.01 & 2.19 & 2.08 & 1.56 & 3.29 & 2.35 & 3.82 & 7.76 & 2.59 & 2.97 \\
\hline Total & 98.11 & 97.69 & 98.35 & 98.05 & 98.01 & 98.01 & 97.85 & 97.94 & 97.81 & 98.52 & 98.90 & 98.38 & 98.34 \\
\hline $\mathrm{Mg} \#$ & 47.18 & 49.78 & 49.28 & 48.53 & 48.55 & 49.79 & 48.20 & 48.45 & 46.68 & 60.58 & 60.99 & 37.73 & 36.68 \\
\hline $\mathrm{Cr}$ & 31 & 35 & 54 & 12 & 29 & 30 & 32 & 11 & 5 & 192 & 280 & 31 & 32 \\
\hline $\mathrm{Ni}$ & 77 & 99 & 87 & 74 & 74 & 83 & 82 & 74 & 68 & 125 & 169 & 56 & 57 \\
\hline Co & 79 & 70 & 76 & 53 & 57 & 59 & 60 & 58 & 58 & 75 & 61 & 37 & 41 \\
\hline V & 274 & 527 & 272 & 427 & 392 & 424 & 422 & 416 & 434 & 254 & 212 & 382 & 392 \\
\hline $\mathrm{Cu}$ & 113 & 96 & 113 & 63 & 85 & 72 & 79 & 63 & 79 & 181 & 125 & 204 & 200 \\
\hline $\mathrm{Zn}$ & 92 & 105 & 92 & 106 & 104 & 106 & 115 & 104 & 112 & 69 & 66 & 118 & 135 \\
\hline $\mathrm{S}$ & 200 & n.d. & 160 & n.d. & n.d. & n.d. & n.d. & n.d. & n.d. & 200 & 160 & n.d. & n.d. \\
\hline $\mathrm{Rb}$ & 52 & 52 & 46 & 57 & 52 & 51 & 69 & 57 & 66 & 61 & 53 & 38 & 36 \\
\hline $\mathrm{Ba}$ & 839 & 761 & 864 & 750 & 1178 & 853 & 1167 & 873 & 996 & 1433 & 728 & 460 & 426 \\
\hline $\mathrm{Sr}$ & 778 & 624 & 788 & 712 & 836 & 766 & 984 & 701 & 867 & 508 & 1199 & 630 & 618 \\
\hline $\mathrm{Nb}$ & 36 & 51 & 39 & 66 & 69 & 66 & 72 & 67 & 70 & 47 & 31 & 25 & 25 \\
\hline $\mathrm{Zr}$ & 244 & 245 & 243 & 257 & 258 & 260 & 268 & 254 & 268 & 210 & 265 & 271 & 271 \\
\hline $\mathrm{Y}$ & 31 & 29 & 31 & 29 & 29 & 30 & 29 & 28 & 31 & 33 & 50 & 39 & 38 \\
\hline $\mathrm{Th}$ & 1 & 5 & n.d. & 4 & 4 & 5 & 6 & 6 & 6 & 1 & n.d. & 5 & 5 \\
\hline U & 1 & 2 & 4 & 1 & 1 & 2 & 2 & 1 & 1 & n.d. & n.d. & n.d. & 1 \\
\hline $\mathrm{La}$ & 16 & n.d. & 26 & n.d. & n.d. & n.d. & n.d. & n.d. & n.d. & 11 & 31 & n.d. & n.d. \\
\hline $\mathrm{Ce}$ & 92 & n.d. & 82 & n.d. & n.d. & n.d. & n.d. & n.d. & n.d. & 71 & 135 & n.d. & n.d. \\
\hline $\mathrm{Nd}$ & 48 & n.d. & 36 & n.d. & n.d. & n.d. & n.d. & n.d. & n.d. & 30 & 50 & n.d. & n.d. \\
\hline
\end{tabular}

Tab. $2-2$ 


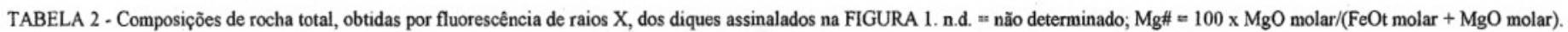

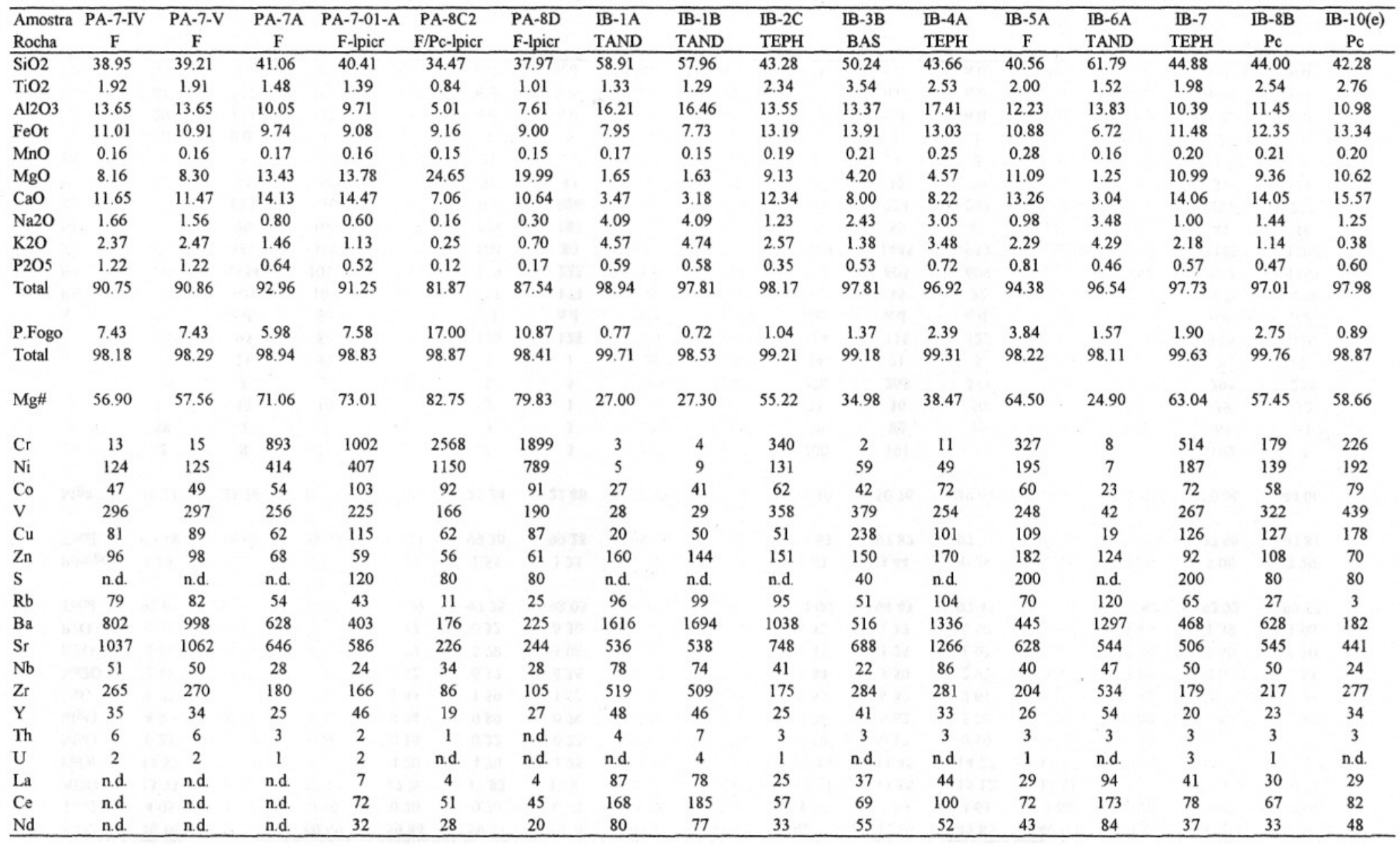


TABELA 2 - Composições de rocha total, obtidas por fluorescência de raios X, dos diques assinalados na FIGURA 1. n.d. = não determinado; $\mathrm{MgH} \mathrm{=} 100 \times \mathrm{xgO}$ molar/(FeOt molar + $\mathrm{MgO}$ molar).

\begin{tabular}{|c|c|c|c|c|c|c|c|c|c|c|c|c|c|c|c|}
\hline Amostra & IB- $14 \mathrm{c} 2$ & IB-16-1 & IB-16-2 & IB-17-Ia & IB-17-Ib & IB-17-II & IB-17-V & IB-17-VIIa & B-17-VIIb & IB-17-VIIc & IB-17-VIII & IB-17-IXa & IB-17-IXb & IB-17-IXc & IB-17-Xb \\
\hline Rocha & BAS & TRC & TRC & TRC & TRC & TRC & TEPH & F/TEPH & TEPH & TEPH & BAS & F & TEPH & TEPH & TEPH \\
\hline$\overline{\mathrm{SiO} 2}$ & 46.46 & 59.69 & 60.69 & 59.84 & 59.35 & 59.78 & 41.31 & 40.97 & 42.77 & 42.86 & 45.85 & 40.90 & 41.90 & 41.27 & 42.95 \\
\hline $\mathrm{TiO} 2$ & 4.05 & 0.73 & 0.56 & 0.70 & 0.70 & 0.72 & 3.28 & 3.26 & 3.53 & 3.53 & 3.63 & 3.68 & 3.72 & 3.66 & 3.80 \\
\hline $\mathrm{Al} 2 \mathrm{O} 3$ & 13.73 & 17.85 & 17.37 & 17.76 & 17.82 & 17.81 & 12.56 & 12.67 & 13.74 & 13.88 & 15.12 & 13.61 & 14.14 & 13.69 & 14.26 \\
\hline $\mathrm{FeOt}$ & 14.32 & 5.47 & 5.61 & 4.70 & 4.70 & 4.75 & 11.88 & 11.24 & 11.44 & 11.45 & 14.27 & 11.86 & 11.52 & 11.61 & 12.19 \\
\hline $\mathrm{MnO}$ & 0.23 & 0.19 & 0.26 & 0.19 & 0.22 & 0.22 & 0.17 & 0.16 & 0.14 & 0.17 & 0.19 & 0.12 & 0.18 & 0.15 & 0.19 \\
\hline $\mathrm{MgO}$ & 4.95 & 0.93 & 0.75 & 0.94 & 0.89 & 0.79 & 9.64 & 8.30 & 6.76 & 6.62 & 5.26 & 6.55 & 6.09 & 6.53 & 5.39 \\
\hline $\mathrm{CaO}$ & 9.73 & 1.22 & 1.21 & 1.43 & 1.59 & 1.52 & 9.38 & 9.93 & 9.53 & 9.80 & 8.61 & 9.63 & 9.43 & 10.38 & 9.05 \\
\hline $\mathrm{Na} 2 \mathrm{O}$ & 2.42 & 6.42 & 6.46 & 6.32 & 6.37 & 6.36 & 2.55 & 2.95 & 3.34 & 3.50 & 2.97 & 2.91 & 2.90 & 2.65 & 2.53 \\
\hline $\mathrm{K} 2 \mathrm{O}$ & 2.04 & 4.74 & 4.60 & 5.79 & 5.79 & 5.80 & 1.23 & 1.12 & 1.43 & 1.25 & 1.03 & 2.41 & 2.54 & 1.60 & 3.50 \\
\hline P2O5 & 0.67 & 0.43 & 0.31 & 0.32 & 0.32 & 0.30 & 1.15 & 1.14 & 1.32 & 1.37 & 0.50 & 1.38 & 1.45 & 1.38 & 1.66 \\
\hline Total & 98.60 & 97.67 & 97.82 & 97.99 & 97.75 & 98.05 & 93.15 & 91.74 & 94.00 & 94.43 & 97.43 & 93.05 & 93.87 & 92.92 & 95.52 \\
\hline P.Fogo & 0.88 & 1.01 & 1.15 & 1.34 & 1.55 & 1.23 & 4.96 & 6.35 & 3.63 & 3.44 & 0.28 & 4.84 & 4.26 & 5.06 & 2.29 \\
\hline Total & 99.48 & 98.68 & 98.97 & 99.33 & 99.30 & 99.28 & 98.11 & 98.09 & 97.63 & 97.87 & 97.71 & 97.89 & 98.13 & 97.98 & 97.81 \\
\hline $\mathrm{Mg} \#$ & 38.11 & 23.26 & 19.23 & 26.29 & 25.24 & 22.86 & 59.12 & 56.82 & 51.30 & 50.76 & 39.64 & 49.60 & 48.51 & 50.06 & 44.06 \\
\hline $\mathrm{Cr}$ & 2 & 8 & 16 & 2 & 1 & 3 & 301 & 267 & 200 & 191 & 6 & 105 & 53 & 102 & 7 \\
\hline $\mathrm{Ni}$ & 58 & 2 & 1 & 3 & 3 & 3 & 220 & 158 & 90 & 82 & 15 & 75 & 58 & 65 & 31 \\
\hline Co & 52 & 43 & 10 & 2 & 2 & 1 & 49 & 41 & 33 & 36 & 50 & 44 & 40 & 39 & 32 \\
\hline V & 403 & 3 & 3 & 8 & 8 & 5 & 249 & 267 & 276 & 265 & 341 & 306 & 295 & 295 & 258 \\
\hline $\mathrm{Cu}$ & 74 & 21 & 37 & 1 & 2 & 1 & 26 & 19 & 24 & 21 & 5 & 13 & 13 & 8 & 7 \\
\hline $\mathrm{Zn}$ & 147 & 95 & 82 & 129 & 126 & 128 & 85 & 100 & 114 & 115 & 122 & 116 & 122 & 115 & 130 \\
\hline $\mathrm{S}$ & n.d. & n.d. & 80 & n.d. & nd. & n.d. & n.d. & n.d. & n.d. & n.d. & n.d. & n.d. & n.d. & n.d. & n.d. \\
\hline $\mathrm{Rb}$ & 99 & 103 & 106 & 172 & 151 & 173 & 41 & 37 & 36 & 35 & 32 & 108 & 106 & 67 & 199 \\
\hline $\mathrm{Ba}$ & 559 & 1354 & 1011 & 204 & 219 & 222 & 528 & 514 & 520 & 605 & 608 & 616 & 754 & 587 & 1387 \\
\hline $\mathrm{Sr}$ & 422 & 381 & 389 & 77 & 104 & 89 & 1167 & 1117 & 1399 & 1445 & 937 & 1221 & 1317 & 1189 & 1200 \\
\hline $\mathrm{Nb}$ & 23 & 99 & 109 & 180 & 178 & 181 & 42 & 44 & 49 & 50 & 45 & 46 & 51 & 47 & 48 \\
\hline $\mathrm{Zr}$ & 293 & 613 & 686 & 838 & 806 & 860 & 186 & 194 & 215 & 224 & 242 & 205 & 221 & 204 & 211 \\
\hline $\mathrm{Y}$ & 42 & 34 & 34 & 41 & 41 & 43 & 27 & 27 & 30 & 32 & 30 & 31 & 33 & 31 & 38 \\
\hline Th & 3 & 5 & 7 & 22 & 21 & 21 & 3 & 5 & 5 & 4 & 3 & 3 & 4 & 6 & 6 \\
\hline U & n.d. & n.d. & 3 & 4 & 4 & 5 & 1 & 1 & 1 & 1 & 1 & 1 & 1 & 2 & 1 \\
\hline $\mathrm{La}$ & 29 & 114 & 117 & n.d. & n.d. & n.d. & n.d. & n.d & nd. & n.d. & n.d. & n.d. & n.d. & n.d. & n.d. \\
\hline $\mathrm{Ce}$ & 81 & 207 & 195 & n.d. & n.d. & n.d. & n.d. & n.d. & n.d. & n.d. & nd. & n.d. & n.d. & n.d. & n.d. \\
\hline $\mathrm{Nd}$ & 45 & 93 & 75 & n.d. & n.d. & n.d. & n.d. & n.d. & n.d. & n.d. & n.d. & n.d. & n.d. & n.d. & n.d. \\
\hline
\end{tabular}


A FIGURA 2 apresenta a classificação das amostras relacionadas na TABELA 2 e de BELLIENI et al. (1990) segundo o diagrama TAS ou álcalis versus sílica (in LE MAITRE, 1989). No caso das amostras da TABELA 2, os lamprófiros picríticos plotam no campo dos foiditos e picrobasaltos (a amostra PA-8C2 não aparece no diagrama, por apresentar $\mathrm{SiO}_{2}$ $<35 \%$ ), os monchiquitos e camptonitos no campo dos foiditos, os álcali basaltos no dos tefritos, e a rocha básica de PA-7 (FOTOS 2 e 5) no campo dos basaltos (FIGURA 2C). Os diques da Ilha de São Sebastião situam-se nos campos dos traquitos, traquiandesitos, basanitos/tefritos, basaltos e picrobasaltos (FIGURA 2D).

BELLIENI et al. (1990) distinguem, dentre os diques da Ilha de São Sebastião, aqueles do Cretáceo Inferior (EC), representados, segundo a classificação química de LA ROCHE et al. (1980), pelos termos básicos andesibasaltos, latibasaltos e latiandesitos e pelos termos ácidos dacitos e riodacitos, aparecendo nestes últimos, além de plagioclásio, augita e titanomagnetita, a pigeonita e, subordinadamente, a apatita. Estas rochas estão indicadas na FIGURA 2B como diques EC, plotando nos campos dos basaltos, traquibasaltos, andesitos basálticos, traquiandesitos e no limite traquito/dacito. Não há continuidade composicional a partir dos termos mais básicos para os mais ácidos. Os diques do Cretáceo Superior (LC) são classificados no diagrama de LA ROCHE et al. (1980) como basanitos, tefritos e álcali basaltos. No diagrama TAS, plotam no campo dos tefritos/basanitos, próximo ao limite com os campos dos traquibasaltos e basaltos (FIGURA 2B), como também ocorre com as amostras da Ponta do Baraqueçaba (FIGURA 2C). Os autores mencionam que os diques LC são constituídos por rochas usualmente porfiríticas, com fenocristais de piroxênio em matriz microcristalina.

As análises relativas aos stocks alcalinos plotam no campo dos traquitos no diagrama TAS, que equivale ao campo dos sienitos do diagrama QAPF (in LE MAITRE $o p$. cit.), exceto uma amostra de tefrifonolito (equivalente ao monzosienito).

A FIGURA 3 mostra o comportamento dos óxidos dos elementos maiores das amostras do Município de São Sebastião em função da sílica. As amostras classificadas no diagrama TAS como basaltos (CB-11-2, PA-7-I e PA-7-VIII), com $\mathrm{SiO}_{2}>47 \%$, apresentam comportamento químico distinto das demais. Os álcali basaltos (amostras com a sigla PB e o conjunto PA-1), classificados pelo diagrama TAS como tefritos (FIGURA 2C), apresentam concentrações mais elevadas de $\mathrm{TiO}_{2}, \mathrm{FeO}_{\mathrm{t}}$ e $\mathrm{K}_{2} \mathrm{O}$. As amostras $\mathrm{PB}$ são as mais enriquecidas em $\mathrm{Al}_{2} \mathrm{O}_{3}$ e $\mathrm{Na}_{2} \mathrm{O}$. Os tefritos apresentam os teores mais baixos de $\mathrm{MgO}$, contrapondo-se aos lamprófiros picríticos (PA-8C2 e PA-8D).

Um conjuto de amostras (CB-7-2B, CB-72C, PA-5, PA-7-IV, PA-7-V e PP-3-3), quimicamente classificadas como foiditos, destacase por apresentar $\mathrm{P}_{2} \mathrm{O}_{5}>1 \%$. Individualizando estas amostras nos demais diagramas da FIGURA 3, nota-se que ocupam regiões distintas daquelas dos tefritos e lamprófiros picríticos.

As amostras CB-16 (corte da entrada SP-55) e CB-9-2 (praia do Cabelo Gordo) são composicionalmente bastante semelhantes principalmente quanto às concentrações mais elevadas de $\mathrm{CaO}$.

Para a Ilha de São Sebastião (FIGURA 4), as amostras classificadas como traquitos e traquiandesitos pelo diagrama TAS apresentam os teores mais baixos de $\mathrm{TiO}_{2}, \mathrm{FeO}_{\mathrm{t}}, \mathrm{MgO}, \mathrm{CaO}$ e $\mathrm{P}_{2} \mathrm{O}_{5}$ e os mais altos de $\mathrm{SiO}_{2}, \mathrm{Al}_{2} \mathrm{O}_{3}, \mathrm{~K}_{2} \mathrm{O}$ e $\mathrm{Na}_{2} \mathrm{O}$.

Como os basaltos do Município de São Sebastião, os da ilha apresentam concentrações de $-\mathrm{TiO}_{2}>3 \%$, de $\mathrm{Al}_{2} \mathrm{O}_{3}$ e $\mathrm{FeOt}$ equivalentes ou mais elevados e de $\mathrm{MgO}$ mais baixas do que nas demais rochas.

As rochas do ponto IB-17 (Ponta Larga), que também aparecem como xenólito na encaixante alcalina (FOTO 4) e que são quimicamente classificadas como tefritos, destacam-se pelos teores de $\mathrm{P}_{2} \mathrm{O}_{5}>1 \%$, de $\mathrm{TiO}_{2}, \mathrm{Al}_{2} \mathrm{O}_{3}$ e $\mathrm{Na}_{2} \mathrm{O}$ mais elevados e de $\mathrm{MgO}$ e $\mathrm{CaO}$ mais baixos do que aqueles dos demais tefritos da Ilha. Quando estes teores são comparados aos dos tefritos do ponto PA-1, observa-se que, em IB-17, $\mathrm{TiO}_{2}, \mathrm{Na}_{2} \mathrm{O}$ e $\mathrm{P}_{2} \mathrm{O}_{5}$ são mais elevados, $\mathrm{FeO}_{\mathrm{t}}$ e $\mathrm{CaO}$ mais baixos e $\mathrm{MgO}$ e $\mathrm{Al}_{2} \mathrm{O}_{3}$ são equivalentes aos de PA-1.

As rochas de BELLIENI et al. (1990) classificadas como basanitos, tefritos e álcali basalto pelo diagrama de LA ROCHE et al. (1980) apresentam as mesmas características geoquímicas dos álcali basaltos do Município de São Sebastião, ou seja: $\mathrm{SiO}_{2}$ entre 40 e $47 \%, \mathrm{TiO}_{2}$ : 2-3\%, $\mathrm{Al}_{2} \mathrm{O}_{3}: 13-18 \%$ (apesar do intervalo de variação ser amplo, as concentrações de $\mathrm{Al}_{2} \mathrm{O}_{3}$ são mais baixas do que as dos stocks alcalinos); $\mathrm{FeO}_{\mathrm{t}}: 10-14 \%$, MgO: 5-12\%, $\mathrm{CaO}: 7$ a $14 \%$, $\mathrm{Na}_{2} \mathrm{O}: 1-14 \%, \mathrm{~K}_{2} \mathrm{O}: 2-3,2 \%$, e $\mathrm{P}_{2} \mathrm{O}_{5}: 0,35$ e $0,75 \%$. 

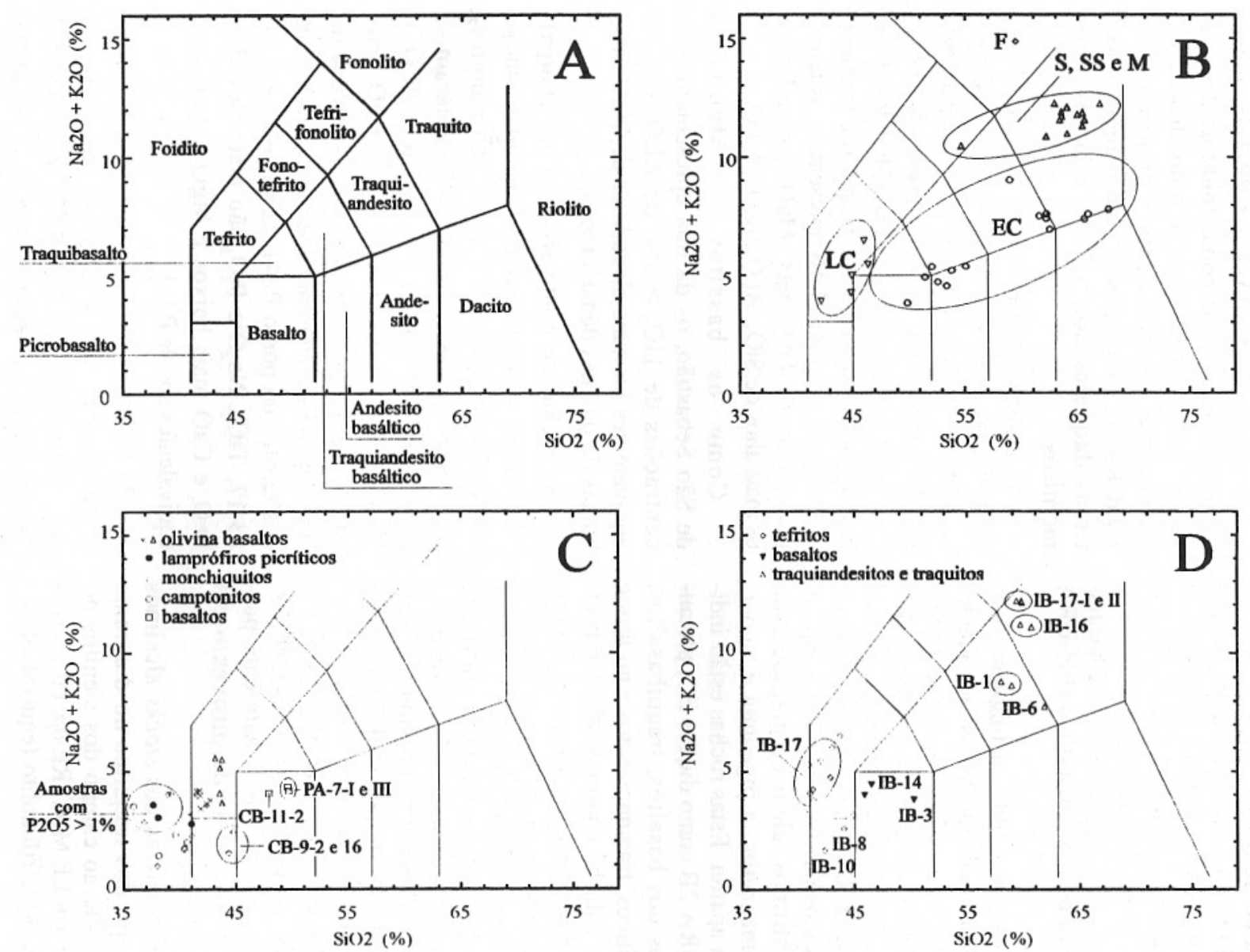

FIGURA 2 - A. Diagrama TAS (álcalis x sílica) para classificação de rochas ígneas vulcânicas (in: LE MAITRE, 1989). B. Amostras da Ilha de São Sebastião analisadas por BELLIENI et al. (1990). LC = diques do Cretáceo Superior; EC = diques do Cretáceo Inferior. Stocks alcalinos de Serraria, São Sebastião e Mirante. F = dique de fonólito. C. Amostras listadas na TABELA 1 com as siglas PG, PB, CB, PP e PA. D. Amostras da Ilha de São Sebastião listadas na TABELA 1 com a sigla IB. 

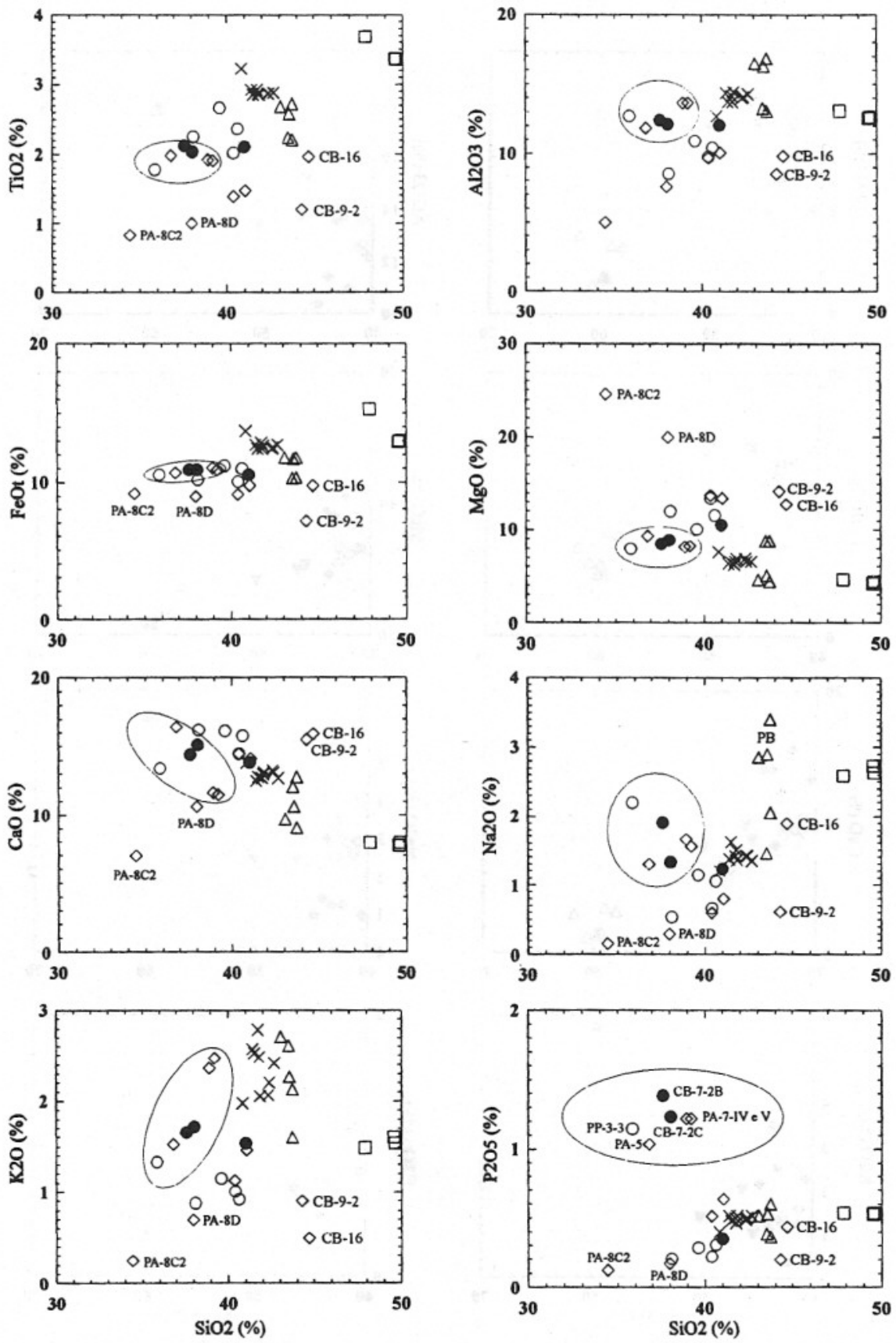

FIGURA 3 - Diagramas de variação dos óxidos dos elementos maiores versus sílica das amostras PG, PB, CB, PP e PA (TABELA 1). $\diamond=$ lamprófiros picríticos; $\bigcirc=$ monchiquitos; $\bigcirc=$ camptonitos; $\Delta=$ tefritos $(\mathrm{X}=\mathrm{PA}-1) ; \square=$ basaltos. Nos diagramas estão assinalados os campos das amostras com $\mathrm{P}_{2} \mathrm{O}_{5}>1 \%$. 

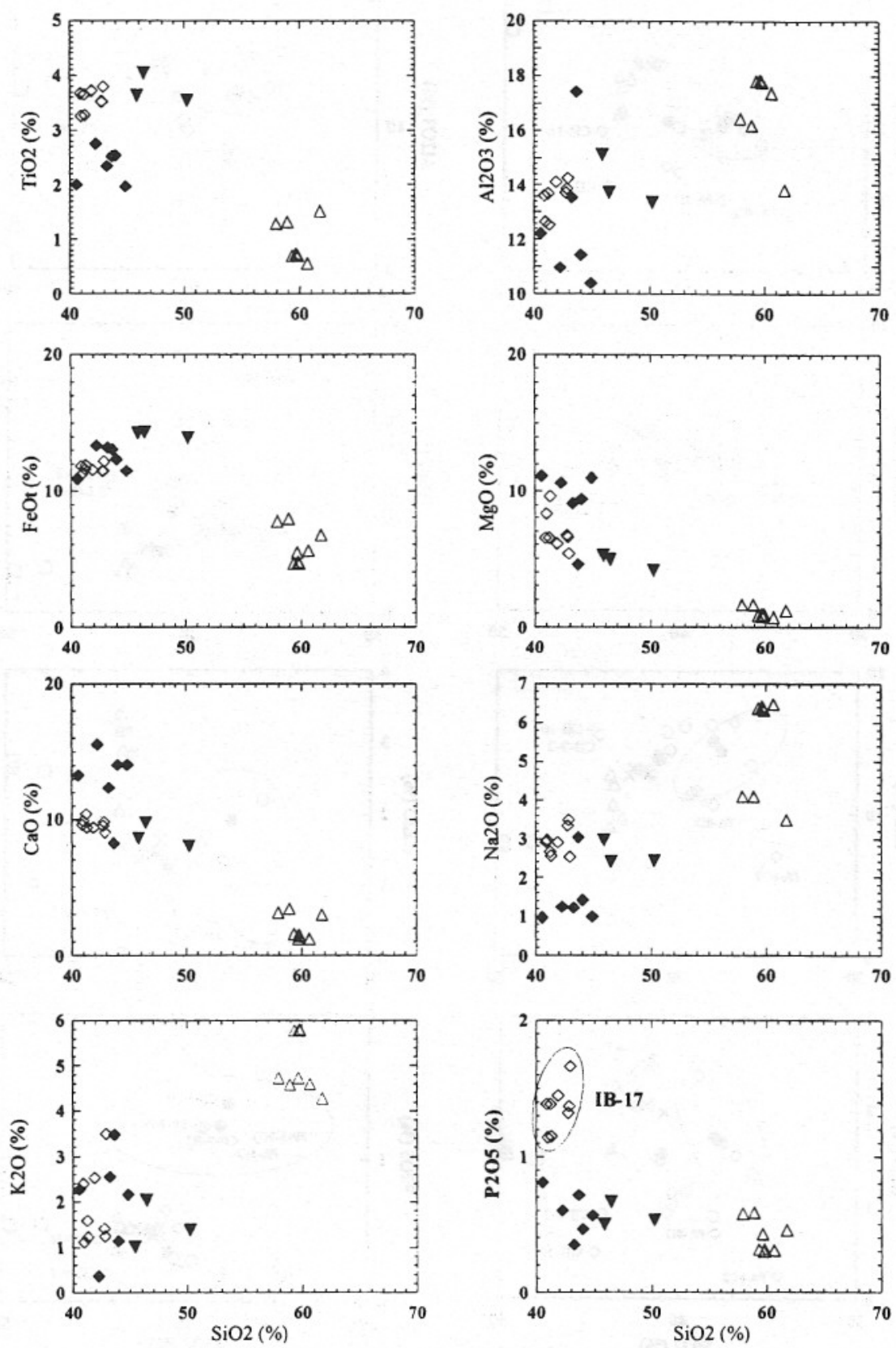

FIGURA 4 - Diagramas de variação dos óxidos dos elementos maiores versus sílica das amostras IB (TABELA 1). $\diamond=$ tefritos; $\diamond=$ tefritos do ponto IB-17; $\nabla=$ basaltos; $\Delta=$ traquiandesitos e traquitos. 
Curiosamente não foram encontrados, até o presente momento, monchiquitos/camptonitos na Ilha de São Sebastião, fato também comprovado pela geoquímica, já que não existem pontos no campo dos foiditos nas FIGURAS 2B e 2D.

\subsection{Elementos traços}

A TABELA 3 apresenta os resultados das análises de elementos traços por NAA e ICPMS que, normalizados segundo os valores para o manto primitivo de SUN \& McDONOUGH (1989) e substituindo fósforo por $\mathrm{P}_{2} \mathrm{O}_{5}$, estão representados nos diagramas multi-elementares da FIGURA 5.

Como uma primeira aproximação, tomou-se a amostra PA-1 como representativa dos álcali basaltos. Os padrões de abundância da FIGURA $5 \mathrm{~A}$ mostram concentrações de $\mathrm{Ba}$ (anomalia positiva), $\mathrm{Sr}, \mathrm{P}_{2} \mathrm{O}_{5}$ e $\mathrm{Zr}$ mais elevadas que as demais amostras analisadas e anomalias negativas de Ti. As amostras CB-7-2B e PA-5, cujos padrões são parcialmente semelhantes ao de PA-1, apresentam, diferentemente desta, anomalia de $\mathrm{K}$ negativa. Os padrões de abundância da FIGURA 5B representam os monchiquitos/camptonitos, sendo que as anomalias de $\mathrm{P}_{2} \mathrm{O}_{5}$ são negativas, de Li positivas; as amostras PG-1-5 e PG-1-6A não apresentam anomalias de $\mathrm{Nb}$ e Ti. A FIGURA 5C corresponde aos lamprófiros picríticos, com as concentrações mais baixas de elementos incompatíveis $(\mathrm{Rb}$, $\mathrm{Ba}, \mathrm{Sr}, \mathrm{P}_{2} \mathrm{O}_{5}, \mathrm{Zr}$ e Ti). As amostras PA-8C2 e PA-8D não apresentam anomalias de Ti.

Em relação aos elementos terras raras, os álcali basaltos apresentam razões $(\mathrm{La} / \mathrm{Yb})_{\mathrm{N}} \approx 14$, os camptonitos/monchiquitos 13 e os lamprófiros picríticos 10 .

A amostra IB-10(e) da Ilha de São Sebastião (microteralito) apresenta um padrão distinto dos demais, principalmente quanto ao comportamento dos elementos entre $\mathrm{Cs}$ e $\mathrm{Li}$ (FIGURA 5D). Para essa amostra, $(\mathrm{La} / \mathrm{Yb})_{\mathrm{N}} \approx 12 \mathrm{e}$ o seu perfil é caracterizado pelas anomalias negativas de $\mathrm{Rb}, \mathrm{Nb}, \mathrm{K}$, Ti e Sr.

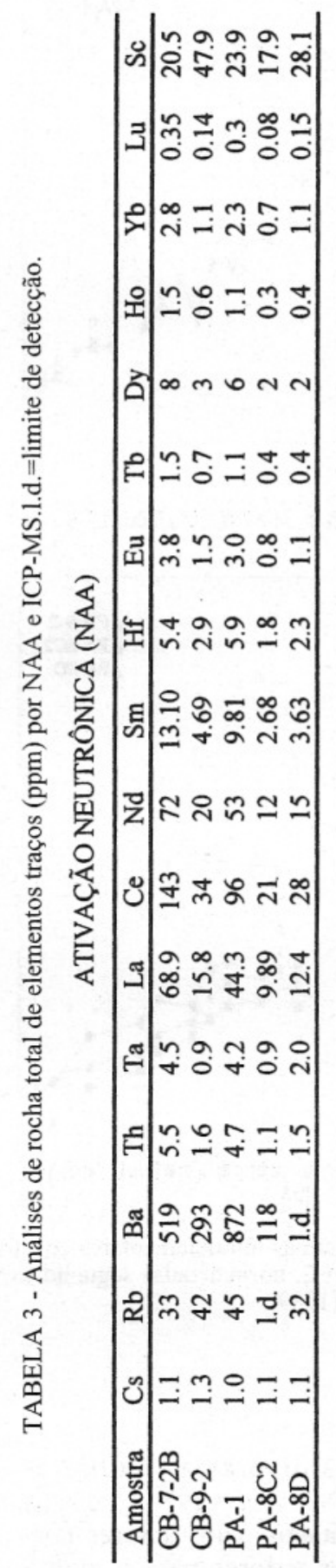



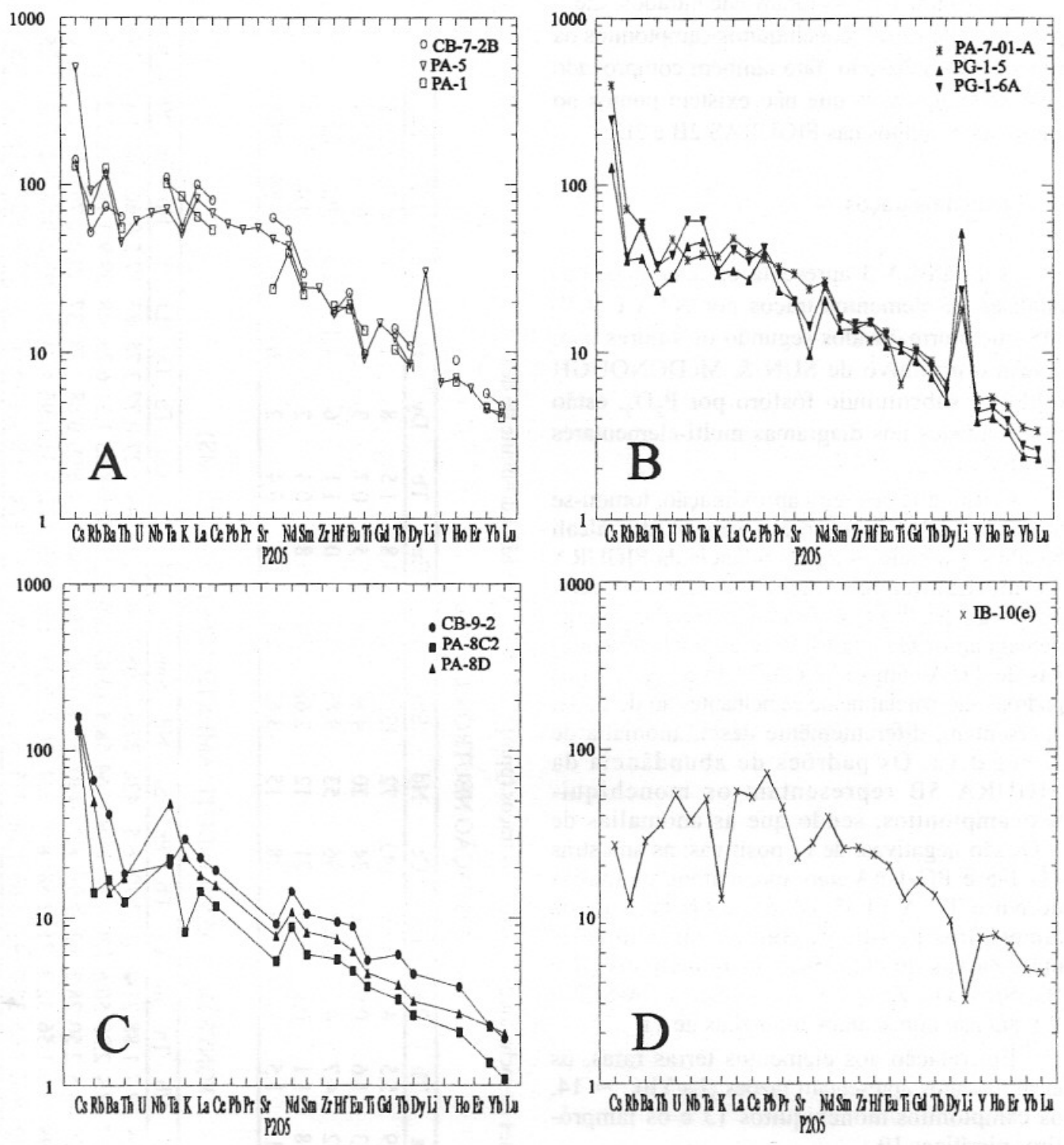

FIGURA 5 - Diagramas multielementares construídos utilizando-se as análises da TABELA 3 e K, Ti e $\mathrm{P}_{2} \mathrm{O}_{5}$ a partir da TABELA 2, normalizadas segundo os valores dos elementos para o manto primitivo segundo SUN \& McDONOUGH (1989).

Refazendo-se os diagramas multielementares de BELLIENI et al. (1990), com os dados de ICP apresentados pelos autores normalizados segundo os valores para o manto primitivo de SUN \& McDONOUGH (1989), observa-se que os diques EC são representados por padrões com anomalias negativas de $\mathrm{Nb}$, $\mathrm{Sr}, \mathrm{P}_{2} \mathrm{O}_{5}$ e Ti. Pelo comportamento geoquímico, aqueles autores associam os diques $\mathrm{EC}$ às vulcânicas ácidas estratóides enriquecidas em elementos incompatíveis do tipo Chapecó do norte da Bacia do Paraná (e.g. PICCIRILLO et al. 1988) e aos diques básicos e ácidos da faixa Santos-Rio de Janeiro (e.g. COMINCHIARAMONTI et al., 1983), considerando aqueles diques extensões dos diques EC da Ilha.

Os padrões de abundância de dois diques LC (tefrito e basanito) assemelham-se aos da FIGURA 5A (álcali basaltos), exceto pelo maior enriquecimento em $\mathrm{Rb}$ e $\mathrm{K}$.

Os padrões de abundância dos stocks de Serraria, São Sebastião e Mirante analisados por 
BELLIENI et al. (1990) apresentam forte anomalia positiva de $\mathrm{K}$, fortes anomalias negativas de $\mathrm{Sr}$ e $\mathrm{Ti}$ e menos pronunciada de $\mathrm{Ba}$. A amostra de dique de fonólito analisado pelos autores mostra enriquecimento em elementos terras raras, apresenta fortes anomalias positivas de $\mathrm{Nb}, \mathrm{La}, \mathrm{Nd}$ e $\mathrm{Zr}$ e fortes anomalias negativas de $\mathrm{Ba}, \mathrm{Sr}, \mathrm{P}_{2} \mathrm{O}_{5}$ e Ti.

Como uma primeira tentativa de correlacionar geneticamente os lamprófiros alcalinos do município de São Sebastião, GARDA (1995) testou com o programa Mix'n'Mac (MASON, 1987), que utiliza o método dos mínimos quadrados, concentrações de elementos maiores e dados de química mineral, a possibilidade de geração dos lamprófiros a partir dos álcali basaltos encontrados na região. Os resultados mostraram que os monchiquitos e camptomitos podem se formar com o acréscimo de voláteis (e.g. $\mathrm{H}_{2} \mathrm{O}$ e $\mathrm{CO}_{2}$ ) aos magmas álcali basálticos, propiciando o aparecimento de kaersutita e biotita e dos glóbulos preenchidos por carbonato e analcima. Os lamprófiros picríticos poderiam corresponder aos termos residuais na evolução dos magmas lamprofíricos, o que explicaria a baixa concentração de elementos incompatíveis e a abundância de olivina (e cromita) nessas rochas.

COUTINHO \& ENS (1992) são da opinião de que as fases residuais da cristalização dos lamprófiros alcalinos da região entre São Sebastião e Juréia, pelo preenchimento de estruturas globulares por calcita, bem como pela carbonatização da matriz e fenocristais, devem ter-se enriquecido notavelmente em substâncias carbonáticas. Citam que, nas proximidades de Boiçucanga, são encontrados corpos tabulares de espessura métrica, dispostos lateralmente ou em continuidade com diques lamprofíricos, formados por brechas com fragmentos de rocha encaixante totalmente carbonatizados e silicificados.
Na INTRODUÇÃO, foram citadas algumas ocorrências de corpos carbonatíticos, tanto no Litoral Norte, como no Litoral Sul do Estado de São Paulo. Ainda que os dados apresentados não sejam suficientes para comprovar a influência de magmas carbonatíticos na geração dos lamprófiros alcalinos da área de estudo, esta é uma hipótese que está sendo apontada e que deverá ser verificada futuramente.

\subsection{Isótopos de $\mathrm{Sr}$}

A TABELA 4 apresenta as razões isotópicas de $\mathrm{Sr}$ de seis amostras da área de estudo, incluindo os valores calculados de ${ }^{87} \mathrm{Rb} /{ }^{86} \mathrm{Sr}$, usando os dados de $\mathrm{Rb}$ e $\mathrm{Sr}$ das TABELAS 2 e 3 (não foi possível a obtenção de dados mais precisos por diluição isotópica).

A FIGURA 6 apresenta a isócrona de referência de 80,8 Ma, obtida por MONTESLAUAR et al. (1995), com razão inicial = 0,70495 e MSWD $=5,3234$, os dados da TABELA 4 e os de BELLIENI et al. (1990). Estes autores obtiveram razões ${ }^{87} \mathrm{Sr} /{ }^{86} \mathrm{Sr}$ iniciais de 0,70462 para o basanito (SSG-3) e 0,70433 para o tefrito (SSG-2) da Ilha de São Sebastião, inferiores aos valores para os stocks de Serraria e Mirante (respectivamente 0,70533 e 0,70507 ), o que para eles indica diferentes fontes mantélicas (Time-integrated mantle source materials) para os diques LC e stocks. Se estes diques forem realmente equivalentes aos álcali basaltos do continente, então uma fonte mantélica distinta daquela que gerou os stocks pode ter produzido os álcali basaltos da Ilha e do continente.

Observa-se, ainda, que a razão ${ }^{87} \mathrm{Sr} /{ }^{86} \mathrm{Sr}$ inicial obtida para o traquito IB-16-1 $(0,7048)$ aproxima-se dos valores citados para os stocks, enquanto a da amostra IB-10(e) é a mais baixa entre as amostras analisadas $(0,7042)$.

TABELA 4 - Razões ${ }^{87} \mathrm{Sr} /{ }^{86} \mathrm{Sr}$ medidas e ${ }^{87} \mathrm{Rb} /{ }^{86} \mathrm{Sr}$ calculadas a partir das concentrações de $\mathrm{Sr}$ e $\mathrm{Rb}$ das TABELAS 2 e 3.

\begin{tabular}{lcccc}
\hline \multicolumn{1}{c}{ Amostra } & $\begin{array}{c}\mathrm{Sr} \\
(\mathrm{ppm})\end{array}$ & $\begin{array}{c}\mathrm{Rb} \\
(\mathrm{ppm})\end{array}$ & $\begin{array}{c}87 \mathrm{Sr} / 86 \mathrm{Sr} \\
\text { (medido) }\end{array}$ & $\begin{array}{c}87 \mathrm{Rb} / 86 \mathrm{Sr} \\
\text { (calculado) }\end{array}$ \\
\hline PA-7-01-A & 624 & 45.5 & 0.705847 & 0.2111 \\
PA-5 & 1164.2 & 58.3 & 0.705706 & 0.1455 \\
PG-1-6A & 429.9 & 23.5 & 0.705168 & 0.1583 \\
IB-1B & 538.0 & 99.0 & 0.706493 & 0.5328 \\
IB-16-1 & 381.0 & 103.0 & 0.705645 & 0.7827 \\
IB-10(e) & 475.3 & 7.6 & 0.704252 & 0.0462 \\
\hline
\end{tabular}




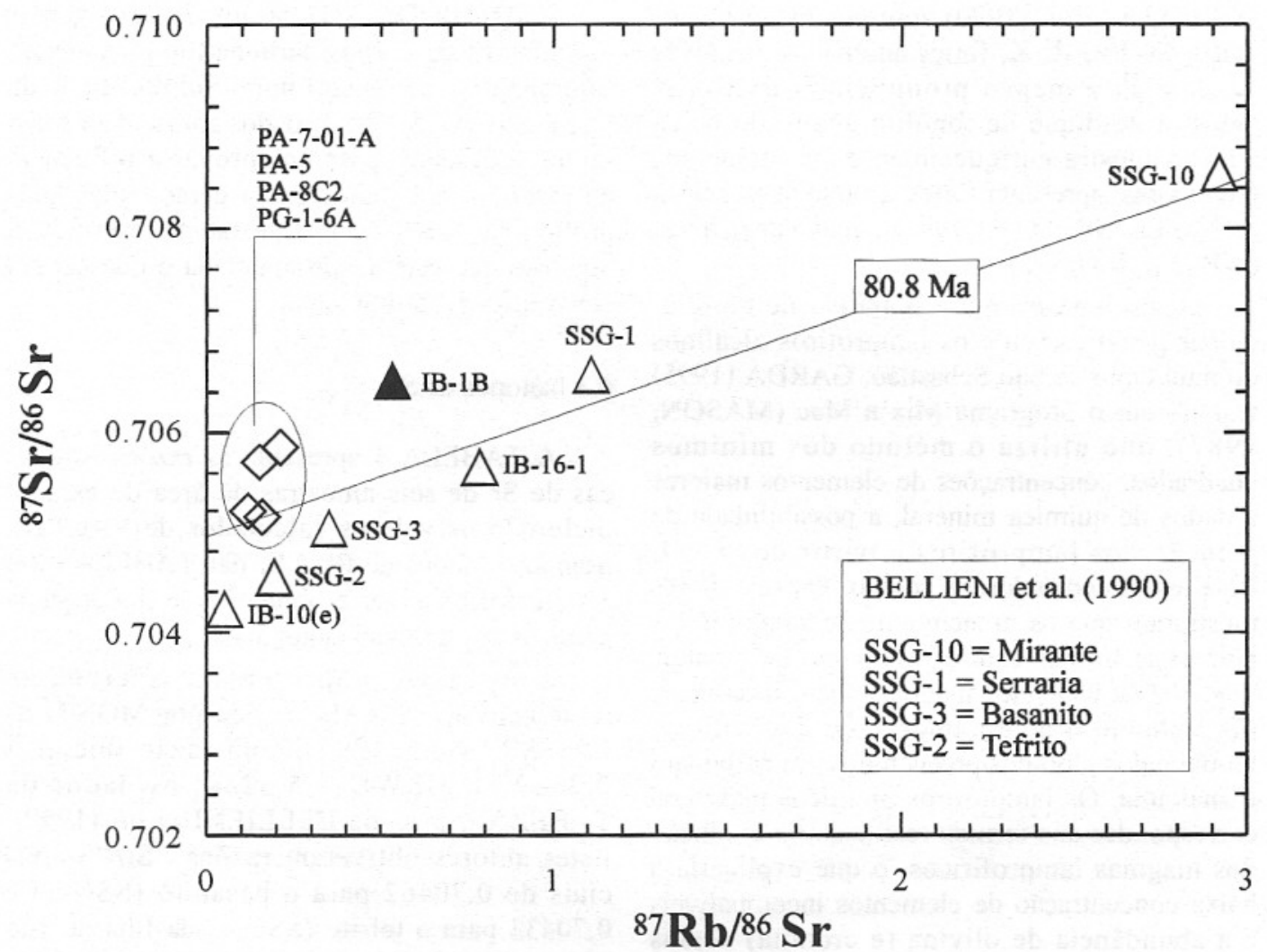

FIGURA 6 - Razões ${ }^{87} \mathrm{Sr} /{ }^{86} \mathrm{Sr}$ versus razões ${ }^{87} \mathrm{Rb} /{ }^{86} \mathrm{Sr}$ (dados da TABELA 4). Isócrona de 80,8 Ma de MONTES-LAUAR et al. $(1995)$, para a qual: MSWD = 5,3234 e razão inicial $=0,70495$.

\section{DISCUSSÃO}

A seqüência de eventos magmáticos ocorrida no Brasil Meridional iniciou-se, segundo ALMEIDA (1976), com o magmatismo basáltico toleítico da Bacia do Paraná (Formação Serra Geral) entre o Jurássico Superior e o Cretáceo Inferior, atualmente situado em $133 \pm 1 \mathrm{Ma}$ e com duração inferior a $1 \mathrm{Ma}$ (RENNE et al., 1992). Enquanto o Arco de Ponta Grossa, no Cretáceo Inferior, foi invadido por enxames de diques de diabásio com direção preferencial NW, também ocorrendo intrusões de rochas alcalinas com tendências carbonatíticas (Banhadão, Barra do Teixeira, Mato Preto, Tunas e Itapirapuã; ver SONOKI \& GARDA, 1988), a Serra do Mar ficou submetida a fraturas de tensão em que penetraram diques de diabásio de direção NE-ENE e "raros" lamprófiros (descritos por DAMASCENO, 1966). ALMEIDA (op. cit.) assinala que a borda noroeste da Bacia de Santos pode ter atuado como um grande arqueamento ou flexura, permitindo a extrusão de magma basáltico pelas fraturas tensionais que se formaram. Antigos lineamentos de falha devem ter sido reativados, favorecendo o estabelecimento da atividade ígnea. As condições mais energéticas de tectonismo proporcionaram a alta densidade de diques no litoral norte e ilhas. Cessado o magmatismo basáltico, nova fase magmática, desta vez marcadamente alcalina, ocorreu depois do Turoniano ( $89 \mathrm{Ma})$, caracterizada pelas intrusões de Cananéia, São Sebastião, Montão de Trigo, Búzios e Vitória, ocorridas em regiões próximas às falhas tangenciais à Bacia de Santos.

KLEIN et al. (1996) observaram a recorrência do magmatismo basáltico em Nova Iguaçu (RJ), onde um dique de basalto atravessa uma brecha tectônica contendo blocos de gnaisses diversos e de traquitos, e em Cabuçu, onde diques básicos cortam sienitos. Entretanto, os autores alertam para o fato de que lamprófiros ultramáficos filiados às rochas alcalinas são, no campo, muito semelhantes aos basaltos, devendo ser realizados estudos mais aprofundados para sua melhor caracterização e, conseqüentemente, a constatação da recorrência.

Quanto à questão da contemporaneidade dos diques de diabásio e lamprófiros, PICHLER 
\& SANTOS (1955 apud SILVA et al., 1977), estudando algumas rochas básicas de Santos, haviam concluído que os lamprófiros ali presentes, em relação aos diabásios, são intrusões distintas de idade geológica diversa, onde os "primeiros teriam consolidação próxima à superfície e os últimos, em profundidade".

Quanto às relações de idade entre os lamprófiros e as rochas alcalinas, COUTINHO \& MELCHER (1973) constataram que, na Ilha Montão de Trigo, elas são ambíguas, citando que num dos afloramentos a nordeste da ilha, o corpo teralítico é cortado por um dique de microfoiaíto rico em xenólitos básicos e este é, por sua vez, cortado por um dique de lamprófiro microteralítico. Relações semelhantes foram vistas na Ponta Larga e Praia do Bonete, na Ilha de São Sebastião (localidades 9 e 10 assinaladas na FIGURA 1). Entretanto, os álcali basaltos, que aparecem como xenólitos no ponto IB-17 (FOTO 4), são anteriores às intrusivas alcalinas.

VALENTE et al. (1995) classificam os diques de rochas alcalinas do Rio de Janeiro como fonólitos, traquitos e lamprófiros alcalinos (incluindo nefelinitos, basanitos, tefritos e álcali basaltos). Os diques cortam tanto as rochas alcalinas contemporâneas, como gnaisses précambrianos e granitos silurianos. Pelo comportamento geoquímico, os autores consideram que os lamprófiros alcalinos podem representar composições parentais dos traquitos e fonólitos, porém lhes parece improvável que essas rochas estejam correlacionadas somente por processos de cristalização fracionada. Os nefelinitos, basanitos e tefritos podem estar relacionados a fontes mantélicas enriquecidas comparáveis àquelas de basalto de ilhas oceânicas (OIB). As anomalias em $\mathrm{Nb}$ encontradas apontam para a possibilidade de efeitos de contaminação crustal para evolução desses magmas.
Do observado nas porções adjacentes ao Canal de São Sebastião, seria possível que os álcali basaltos, com características geoquímicas de OIB, pudessem gerar rochas alcalinas tanto de tendência mais "carbonatítica" (lamprófiros), como as típicas das ilhas de São Sebastião, Búzios e Vitória? Eles devem ter surgido depois dos basaltos toléticos, com a abertura do oceano, e antes das rochas alcalinas, como sugerido por GARDA (1995). Se houver a participação de voláteis, os álcali basaltos podem evoluir para magmas lamprofíricos, ficando registrada uma característica carbonatítica (COUTINHO \& ENS, 1992). Por outro lado, se ocorrer algum tipo de contaminação, os magmas resultantes poderão ser como aqueles encontrados na Ilha de São Sebastião. A intensificação dos estudos geoquímicos e, principalmente, isotópicos, poderá contribuir à compreensão da evolução desses magmas.

\section{AGRADECIMENTOS}

G.M. Garda agradece a Frederico Bohland Neto, Luciano Pohl, Gustavo Correia de Abreu, Geysa Machado, Paulo Fernandes da Silva e Cristina de Queiroz Telles Maffra, aos técnicos do Centro de Biologia Marinha Adriano Colares da Mota e Álvaro Migotto e a Flávio Miguez pela sua participação nos trabalhos de campo, a José Querino da Silva, Rolf Rettinger, Helen Cauldron, Geoff Denton, Carol Lawson e Steve Eggins pela colaboração nas diversas etapas laboratoriais, às agências financiadoras CNPq e CAPES pela concessão, respectivamente, de bolsa de doutorado (Proc. 140873/90-2) e bolsa PDEE (Proc. 1798/93) e, finalmente, aos relatores anônimos pela revisão do texto e sugestões.

\section{REFERÊNCIAS BIBLIOGRÁFICAS}

ALMEIDA, F.F.M. 1967. Origem e evolução da plataforma brasileira. Rio de Janeiro: DNPM, Bol. Div. Geol. Min. 241:1-36.

ALMEIDA, F.F.M. 1976. The system of continental rifts bordering the Santos Basin, Brazil. In: INTERNATIONAL SYMPOSIUM ON CONTINENTAL MARGINS OF ATLANTIC TYPE, São Paulo, 1975. An. Acad. Bras. Ciênc. 48:15-26 (Suplemento).

ALMEIDA, F.F.M.; HASUI, Y.; PONÇANO, W.L.; DANTAS, A.S.L.; CARNEIRO, C.R.; MELO, M.S. \& BISTRICHI, C.A. 1981. Mapa geológico do Estado de São
Paulo, escala 1:500.000. V. I - Nota explicativa. IPT-DMGA, $126 \mathrm{p}$. (Monografia 6)

AMARAL, G.; BUSHEE, J.; CORDANI, U.G.; KAWASHITA, K. \& REYNOLDS, J.H. 1967. Potassium-argon ages of alkaline rocks from Southern Brazil. Geochim. Cosmochim. Acta 31:117-142.

BELLIENI, G.; MONTES-LAUAR, C.R.; DE MIN, A.; PICCIRILLO, E.M.; CAVAZZINI, G.; MELFI, A.J. \& PACCA, I.G. 1990. Early and Late Cretaceous 
magmatism from São Sebastião Island (SE-Brazil):Geochemistry and petrology. Geochim. Brasil. 4(1):59-83.

CLARKE, D. 1993. NEWPET: Shareware Program for geochemical data treatment. Centre for Earth Resources Research, Memorial University of Newfoundland, Canada.

COMIN-CHIARAMONTI, P.; GOMES, C.B.; PICCIRILLO, E.M. \& RIVALENTI, G. 1983. High-TiO 2 basaltic dikes in the coastline of São Paulo and Rio de Janeiro States (Brazil). Neues Jahrb. Miner. Abbh. 146(2):133-150.

COUTINHO, J.M.V. 1966. "Cone-sheets" traquíticos em São Sebastião. In:CONGRESSO BRASILEIRO DE GEOLOGIA, 20., 1966, Vitória. Resumo das Comunicações...SBG, p. 102-103.

COUTINHO, J.M.V. \& ENS, H.H. 1992. Diques lamprofíricos e diferenciados carbonatíticos da região de São Sebastião e Itanhaém - SP (resultados preliminares). In: CONGRESSO BRASILEIRO DE GEOLOGIA, 37., 1992, São Paulo. Boletim de Resumos Expandidos. SBG/NSP, p. 512-513.

COUTINHO, J.M.V. \& MELCHER, G.C. 1973. Levantamento geológico e petrográfico na ilha do Monte de Trigo, litoral norte de São Paulo, Brasil. R. Bras. Geol. 3(4): 243-256.

COUTINHO, J.M.V.; ENS, H.H.; RODRIGUES, E.P. \& TASSINARI, C.C.G. 1991. Mafic dyke swarms in the northern coast of São Paulo, Brazil (a preliminary report). In: INTERNATIONAL SYMPOSIUM ON MAFIC DYKES, 1991, São Paulo. Extended Abstracts. IG-USP/SBGq, p. 111-115.

DAMASCENO, E.C. 1966. Estudo preliminar dos diques de rochas básicas e ultrabásicas da região de Ubatuba, Estado de São Paulo. An. Acad. bras. Ciênc. 38(2): 293304.

FREITAS, R.O. 1947. Geologia e petrologia da Ilha de São Sebastião. Bol. Fac. Fil. Ciênc. Letras USP 85: 1-244. (Geologia 3)

FREITAS, R.O. 1976. Definição petrológica, estrutural e geotectônica das cintas orogênicas antigas do litoral norte do Estado de São Paulo. São Paulo: Bol. Inst. Geol., 176p.
GARDA, G.M. 1995. Os diques básicos e ultrabásicos da região costeira entre as cidades de São Sebastião e Ubatuba, Estado de São Paulo. São Paulo: Instituto de Geociências da USP, 2v. (Tese de Doutorado)

HASUI, Y.; PONÇANO, W.L.; BISTRICHI, C.A.; STEIN, D.P.; GALVÃO, C.A.C.F.; GIMENEZ, A.F.; ALMEIDA, M.A.; PIRES NETO, A.G.; MELO, M.S. \& SANTOS, M.C.S.R. 1978. Geologia da região administrativa 3 (Vale do Paraíba) e parte da região administrativa 2 (Litoral) do Estado de São Paulo. IPT/DMGA, 78p. (Monografia IPT, 1)

HENNIES, W.T. \& HASUI, Y. 1968. Geocronologia das rochas eruptivas alcalinas da Ilha de São Sebastião, SP. In: CONGRESSO BRASILEIRO DE GEOLOGIA, 22., 1968, Belo Horizonte. Atas... SBG, p. 145-148.

HENNIES, W.T. \& HASUI, Y. 1977. Contribuição ao conhecimento da geologia da Ilha de São Sebastião. In: SIMPÓSIO DE GEOLOGIA REGIONAL, 1., 1977, São Paulo. Atas... SBG/NSP, p. 199-209.

KLEIN, V.C.; ANTONELLO, L.L. \& VALENÇA, J.G. 1996. Diques basálticos pós-alcalinos no Rio de Janeiro, RJ. In: CONGRESSO BRASILEIRO DE GEOLOGIA, 39., 1966, Salvador. Resumos Expandidos... SBG, p. 144-145.

LA ROCHE, H.; LETERRIER, J.; GRANDCLAUDE, P. \& MARCHAL, M. 1980. A classification of volcanic and plutonic rocks using R1R2-diagram and major-element analyses - Its relationships with current nomenclature. Chem. Geol. 29: $183-210$.

LE MAITRE, R.W. (Ed.) 1989. Classification of igneous rocks and glossary of terms. Oxford Blackwell, 193p.

MASON, D.R. 1987. Mix'n'Mac: least-squares mixing program. Glenside (Austrália).

MONTES-LAUAR, C.R.; PACCA, I.G.; MELFI, A.J. \& KAWASHITA, K. 1995. Late Cretaceous alkaline complexes, southeastern Brazil: paleomagnetism and geochronology. Earth. Planet. Sci. Letters 134: 425-440.

PICCIRILLO, E.M.; COMIN-CHIARAMONTI, P.; MELFI, A.J.; STOLFA, D.; BELLIENI, G.; MARQUES, L.S.; GIARETTA, A.; NARDY, A.J.R.; PINESE, J.P.P.; RAPOSO, M.I.B. \& 
ROISENBERG, A. 1988. Petrochemistry of continental flood basalt-rhyolite suites and related intrusives from the Paraná Basin (Brazil). In: PICCIRILLO, E.M. \& MELFI, A.J. (Eds.) The Mesozoic flood volcanism of the Parana Basin: petrogenetic and geophysical aspects. São Paulo: IAG/USP, p. 107-156.

RENNE, P.R.; ERNESTO, M.; PACCA, I.G.; COE, R.S.; GLEN, J.M.; PRÉVOT, M. \& PERRIN, M. 1992. The age of Paraná flood volcanism, rifting of Gondwanaland, and the JurassicCretaceous boundary. Science 258: $975-$ 979.

RICHARD, L.R. 1995. MINPET Version 2.02 - Mineralogical Petrological Data Processing System for Windows. Quebec (Canadá).

SILVA, A.T.S.F.; CHIODI FILHO, C.; CHIODI, D.K. \& PINTO FILHO, W.D. 1977. Projeto Santos-Iguape. v. 1, Geologia. Convênio DNPM-CPRM, 639p.
SONOKI, I.K. \& GARDA, G.M. 1988. Idades $\mathrm{K}$-Ar de rochas alcalinas do Brasil Meridional e Paraguai Oriental: Compilação e adaptação às novas constantes de decaimento. Boletim IGUSP, Série Científica 19:63-85.

SUN, S-S. \& McDONOUGH, W.F. 1989. Chemical and isotopic systematics of oceanic basalts: Implications for mantle composition and processes. In: SAUNDERS, A.D. \& NORRY, N.J. (Eds.) Magmatism in the ocean basins. Geological Society, Special Publication 42:313-345.

ULBRICH, H.H.G.J. \& GOMES, C.B. 1981. Alkaline rocks from continental Brazil. Earth Science Reviews 17:135-154.

VALENTE, S.C.; MEIGHAN, I.G.; FALLICK, A.E. \& ELLAM, R.L. 1995. Os diques de rochas alcalinas do Rio de Janeiro, RJ. In: CONGRESSO BRASILEIRO DE GEOQUÍMICA, 5., 1995, Niterói. Anais... SBGq, CD-ROM. 